\title{
Modeling of thermal storage systems in MILP distributed energy resource models
}

\author{
David Steen $^{\mathrm{a}, \mathrm{b}}$, Michael Stadler ${ }^{\mathrm{a}, \mathrm{c}}$, Gonçalo Cardoso ${ }^{\mathrm{a}, \mathrm{d}}$, Markus Groissböck ${ }^{\mathrm{a}, \mathrm{c}}$, \\ Nicholas DeForest ${ }^{\mathrm{a}}$, Chris Marnay
}

David Steen is an affiliate with Berkeley Lab, USA, and is with Chalmers University of Technology, Sweden Michael Stadler is with Berkeley Lab, USA, and leads the microgrid team at Berkeley Lab as well as the Center for Energy and Innovative Technologies, Austria

Gonçalo Cardoso is with Berkeley Lab, USA, and with Instituto Superior Técnico - University of Lisbon, Portugal Nicholas DeForest is with Berkeley Lab, USA

Markus Groissböck was an affiliate with Berkeley Lab, USA, and with the Center for Energy and Innovative Technologies, Austria

Chris Marnay is a retired Staff Scientist and current affiliate with Berkeley Lab, and is President of Microgrid Design of Mendocino, USA

${ }^{a}$ Lawrence Berkeley National Laboratory

1 Cyclotron Road MS 90R1121

Berkeley CA 94720

USA

${ }^{\mathrm{b}}$ Chalmers University of Technology

Department of Energy and Environment

SE-412 96 Göteborg, Sweden

Phone: +46(0)31-772 1663

${ }^{c}$ Center for Energy and innovative Technologies - CET

Doberggasse 9

A-3681 Hofamt Priel

Austria

${ }^{\mathrm{d}}$ Instituto Superior Técnico - University of Lisbon

Avenida Rovisco Pais 1,

1049-001 Lisboa

Portugal

Corresponding author e-mail: david.steen@ chalmers.se, mobile: 0046-739169596

Second contact: MStadler@lbl.gov

Abstract - Thermal energy storage (TES) and distributed generation technologies, such as combined heat and power (CHP) or photovoltaics (PV), can be used to reduce energy costs and decrease $\mathrm{CO}_{2}$ emissions from buildings by shifting energy consumption to times with less emissions and/or lower energy prices. To determine the feasibility of investing in TES in combination with other distributed energy resources (DER), mixed integer linear programming (MILP) can be used. Such a MILP model is the well-established Distributed Energy Resources Customer Adoption Model (DER-CAM); however, it currently uses only a simplified TES model to guarantee linearity and short run-times. Loss calculations are based only on the energy contained in the storage. This paper presents a new DER-CAM TES model that allows improved tracking of losses based on ambient and storage temperatures, and compares results with the previous version. A multi-layer TES model is introduced that retains linearity and avoids creating an endogenous optimization problem. The improved model increases the accuracy of the estimated storage losses and enables use of heat pumps for low temperature storage charging. Results indicate that the previous model overestimates the attractiveness of TES investments for cases without possibility to invest in heat pumps and underestimates it for some locations when heat pumps are allowed. Despite a variation in optimal technology selection between the two models, the objective function value stays quite stable, illustrating the complexity of optimal DER sizing problems in buildings and microgrids.

Index Terms - distributed energy resources, investment planning, renewables, energy optimization, thermal energy storage

\section{List of Nomenclatures and Symbols}

\section{Abbreviations}


Modeling of thermal storage systems in MILP distributed energy resource models

Submitted to APPLIED ENERGY

\begin{tabular}{|c|c|c|}
\hline 60 & ASHP & air-source heat pump \\
\hline 61 & CHP & combined heat and power \\
\hline 62 & $\mathrm{COP}$ & coefficient of performance \\
\hline 63 & DG & distributed generation \\
\hline 64 & $\mathrm{EV}$ & electric vehicle \\
\hline 65 & FC & fuel cell \\
\hline 66 & GSHP & ground-source heat pump \\
\hline 67 & GT & gas turbine \\
\hline 68 & HP & heat pump \\
\hline 69 & HPR & heat to power ratio \\
\hline 70 & $\mathrm{HT}$ & high temperature \\
\hline 71 & $\mathrm{HX}$ & heat exchange \\
\hline 72 & ICE & internal combustion engine \\
\hline 73 & $\mathrm{LT}$ & low temperature \\
\hline 74 & MILP & mixed integer linear programing \\
\hline 75 & MT & micro turbine \\
\hline 76 & NG & natural gas \\
\hline 77 & PCM & phase changing material \\
\hline 78 & TES & thermal energy storage \\
\hline 79 & \multicolumn{2}{|l|}{ Parameters } \\
\hline 80 & $\eta_{k}^{\text {disch. }}$ & discharge efficiency LT/HT section [-] \\
\hline 81 & $\eta_{k}^{\text {ch. }}$ & charge efficiency LT/HT section [-] \\
\hline 82 & $\theta_{k}^{\text {storage }}$ & storage loss coefficient LT/HT section [-] \\
\hline 83 & $\theta_{k}^{\text {static }}$ & static storage loss coefficient for LT/HT section, due to minimum usable temperature [-] \\
\hline 84 & $\max _{k}^{\text {ch. rate }}$ & maximum charge rate for the LT/HT section $[-]$ \\
\hline 85 & $\max _{k}^{\text {disch. rate }}$ & maximum discharge rate for the LT/HT section [-] \\
\hline 86 & $\mathrm{U}$ & $\mathrm{U}$-value of the thermal energy storage $\left[\mathrm{W} / \mathrm{m}^{2} \mathrm{~K}\right]$ \\
\hline 87 & A & surface area of the thermal energy storage $\left[\mathrm{m}^{2}\right]$ \\
\hline 88 & $\mathrm{cp}$ & specific heat capacity water $[\mathrm{J} / \mathrm{kg} \mathrm{K}]$ \\
\hline 89 & $\mathrm{P}$ & external perimeter of the storage tank $[\mathrm{m}]$ \\
\hline 90 & $\mathrm{H}$ & height of the storage tank $[\mathrm{m}]$ \\
\hline 91 & $\mathrm{r}$ & radius of the storage tank [m] \\
\hline 92 & $\mathrm{X}$ & position of the thermocline level $[\mathrm{m}]$ \\
\hline 93 & $\rho$ & density of water $\left[\mathrm{kg} / \mathrm{m}^{3}\right.$ \\
\hline 94 & $\mathrm{~T}_{t}^{\mathrm{amb}}$ & ambient temperature $\left[{ }^{\circ} \mathrm{C}\right]$ \\
\hline 95 & $\mathrm{~T}_{k}^{\max }$ & maximal operation temperature $\mathrm{LT} / \mathrm{HT} \operatorname{section}\left[{ }^{\circ} \mathrm{C}\right]$ \\
\hline 96 & $\mathrm{~T}_{k}^{\min }$ & minimal operation temperature LT/HT section $\left[{ }^{\circ} \mathrm{C}\right]$ \\
\hline 97 & $\mathrm{E}_{t, k}^{\text {unuse }}$ & unusable energy in the LT/HT section due to temperature restrictions [kWh] \\
\hline 98 & & \\
\hline 99 & \multicolumn{2}{|l|}{ Indices } \\
\hline 100 & $\mathrm{t}$ & hour \\
\hline 101 & $\mathrm{k}$ & section of the storage [LT or HT] \\
\hline 102 & \multicolumn{2}{|c|}{ Decision variables } \\
\hline 103 & $C_{\text {tot }}$ & total annual energy costs $[\$]$ \\
\hline 104 & $C_{\text {elec }}$ & electricity costs $[\$]$ \\
\hline 105 & $C_{D E R}$ & distributed energy resources costs (amortized capital costs of investments) [\$] \\
\hline 106 & $C_{\text {fuel }}$ & fuel costs $[\$]$ \\
\hline 107 & $C_{D R}$ & demand response costs for other non-storage technologies [\$] \\
\hline 108 & $C_{\text {bat }}$ & EV battery degradation costs $[\$]$ \\
\hline $\begin{array}{l}109 \\
110\end{array}$ & $\mathrm{CO}_{2}$ tot & $\begin{array}{l}\text { total annual } \mathrm{CO}_{2} \text { emissions from energy consumption at the building (site and source } \\
\text { emissions) }\left[\mathrm{kgCO}_{2}\right]\end{array}$ \\
\hline 111 & $\mathrm{~V}_{\mathrm{k}}$ & volume of the LT/HT section $\left[\mathrm{m}^{3}\right]$ \\
\hline 112 & $\mathrm{CO}_{2}$ elec & $\mathrm{CO}_{2}$ emissions from electricity consumption $\left[\mathrm{kgCO}_{2}\right]$ \\
\hline 113 & $\mathrm{CO}_{2}$ fuel & $\mathrm{CO}_{2}$ emissions from DG fuel burning $\left[\mathrm{kgCO}_{2}\right]$ \\
\hline 114 & $\mathrm{CO}_{2 \mathrm{EV}}$ & $\mathrm{CO}_{2}$ emissions from EV electricity exchange $\left[\mathrm{kgCO}_{2}\right]$ \\
\hline 115 & & energy sales $[\$]$ \\
\hline 116 & $H_{t, k}^{\text {prov }}$ & heat provided for LT/HT applications [kW] \\
\hline 117 & $H_{t}^{H T}$ prov for $L T$ & HT heat provided for LT applications [kW] \\
\hline
\end{tabular}


Modeling of thermal storage systems in MILP distributed energy resource models Submitted to APPLIED ENERGY

$\begin{array}{ll}118 & H_{t}^{\text {CHP }} \\ 119 & H_{t}^{\text {solar }} \\ 120 & H_{t}^{N G} \\ 121 & H_{t}^{\text {NG chill rec }} \\ 122 & H_{t}^{\text {ASHP }} \\ 123 & H_{t}^{\text {GSHP }} \\ 124 & H_{t, k}^{\text {from TES }} \\ 125 & H_{t, k}^{\text {cons }} \\ 126 & H_{t}^{\text {cooling }} \\ 127 & H_{t}^{\text {refrig }} \\ 128 & H_{t}^{\text {space }} \\ 129 & H_{t}^{\text {water }} \\ 130 & H_{t, k}^{\text {for TES }} \\ 131 & H_{t, k}^{\text {stored }} \\ 132 & \text { Loss }_{t, k} \\ 133 & \text { Cap } \\ 134 & \text { Captorage } \\ & \end{array}$

\author{
heat from CHP [kW] \\ heat from solar thermal $[\mathrm{kW}]$ \\ heat from natural gas $[\mathrm{kW}]$ \\ heat recovered from natural gas chiller $[\mathrm{kW}]$ \\ heat from air source heat pump [kW] \\ heat from ground source heat pump $[\mathrm{kW}]$ \\ usable heat from LT/HT [kW] \\ LT/HT heat consumed $[\mathrm{kW}]$ \\ heat used for absorption building cooling $[\mathrm{kW}]$ \\ heat used for absorption refrigeration [kW] \\ heat used for space heating $[\mathrm{kW}]$ \\ heat used for domestic water heating $[\mathrm{kW}]$ \\ heat used to charge LT/HT section of TES [kW] \\ heat stored in the LT/HT section of TES [kWh] \\ storage heat losses in LT/HT section of TES [kW] \\ total capacity of heat storage [kWh] \\ capacity LT/HT section of TES [kWh]
}

\title{
1. Introduction
}

Distributed Energy Resources (DER) are commonly defined as a set of technologies and strategies with potential to make energy use more efficient, accessible, and environmentally sustainable. These solutions include power generation and combined heat and power (CHP) production using conventional fuel-fired technologies, but also renewable technologies and energy management strategies such as demand response, load shifting and peak-shaving, and storage [1].

Key benefits of DER usage include increased power reliability, higher renewable grid penetration, reduced carbon emissions and improved use of local energy resources [2, 3]; however, DER systems can also lead to higher complexity of system design, as well as additional issues, such as the need for power quality management and access control infrastructure when interconnected to the grid [4].

Storage systems, both electric and thermal, can play a key role in DER deployment, not only by creating a buffer to arbitrage market prices, but also by allowing variable small-scale technology integration and promoting more efficient use of resources [5]. In this context, thermal energy storage (TES) is commonly seen as an effective way to reduce operational costs and increase overall efficiency and capacity factors of micro-CHP units, solar thermal units and heat pumps (HPs) [6-8].

In fact, the combined use of TES and micro-CHP units may significantly reduce utility demand, particularly during peak hours. This has been addressed in previous studies, such as [9], where it is shown that the peak utility demand is reduced by $23 \%$ using CHP coupled with TES for chilled water, compared to only $13 \%$ utility demand reductions achieved with CHP without TES. Similarly, the work described in [10] suggests that TES combined with micro-CHP units in commercial buildings in Chicago can be beneficial from an energy/cost perspective for buildings with a heat demand higher than their electricity demand; however, the TES model used in this particular study is simplified and does not consider any storage losses.

Traditionally, sensible water storage solutions have been used for most heat storage applications [7, 8], although there has been an increased interest in latent heat storage using phase change materials (PCM) over the last decade [11]. Latent heat storage using PCM offers some advantages over sensible hot water tanks, such as higher energy density [12] and less corrosion [11]. Despite the ongoing research, the costs associated with low temperature latent PCM (i.e. 50-100 ${ }^{\circ} \mathrm{C}$ ) are still higher than for sensible water storage [13, 14], although they can be economically competitive under appropriate conditions as demonstrated in [12].

TES has traditionally been modeled using only the first law of thermodynamics [15], meaning that changes in entropy are neglected [7], although analyses based on the second law of thermodynamics, which consider entropy, have become more common in recent decades. This improvement can have a significant impact on achieving optimal design and operation of TES [16], and also increase accuracy of economic results [7], because the model considers not only energy lost to the surrounding but also mixing of hot and cold water in storage. This will affect the performance of other DER connected to the TES, e.g. the efficiency of CHP unit, HP and 
heat exchanger.

Given the wide range of available DER options, the problem of meeting customer energy loads can be addressed by a multitude of solutions. This large search space creates a highly complex problem and identifying optimal DER equipment portfolio and operation options becomes a major challenge. DER can be very valuable, both when considering their economic and environmental benefits; however, choosing the actual energy supply solution is often based on empirical guidelines and rules-of-thumb, which typically lead to sub-optimal system configurations.

To address such DER problems, the Distributed Energy Resources Customer Adoption model (DER-CAM) has been developed at the Lawrence Berkeley National Laboratory [17]. The main output of DER-CAM is the economically and/or environmentally optimal combination of distributed energy conversion, storage and management options. Until now, TES has been modeled in DER-CAM as sensible heat storage, using water as the storage medium, and considering only energy flows through the tank. Storage losses have been estimated solely based on the energy stored, with size and ambient temperature not considered. Although this approach is commonly used in such tools, e.g. [18-20], and provides useful insights, its main drawback is that temperature changes in the tank are not tracked, which limits accurate economic assessment of TES [7]. Temperature changes also affect storage losses and how different heat-consuming and -providing technologies utilize the TES. For example, absorption cooling systems need relatively high input temperatures of at least $80-100^{\circ} \mathrm{C}$ [21], and the existing model is unable to comply directly with these constrains, possibly leading to overestimation of TES economic performance.

This paper contributes to the state of the art by introducing an improved TES model into DER-CAM. Due to the current high cost associated with PCM based TES [13, 14], the model still considers only a sensible heat system using water as the storage medium. Although a model based on the second law of thermodynamics would increase the accuracy, it would result in an endogenous optimization problem formulation when used in investment and planning tools, due to the need of temperature tracking. Such problems can't be solved in MILP models, such as DER-CAM. Furthermore, to capture all benefits of such model it would require increased details on the technologies connected to the TES, such as CHPs, HPs and absorption chillers, resulting in increased need for computational capacity. Hence, the second law of thermodynamics is not considered. Nevertheless, the TES model now introduced estimates storage losses with higher accuracy by considering the ambient temperature and static storage losses (due to a lower temperature threshold in the tank), which were previously not recognized. Furthermore, the new formulation of TES enables storage to be charged by low temperature heat sources, as the storage tank is now modeled with two separate temperature sections for high and low temperature storage.

The changes introduced to the TES model in DER-CAM are analyzed by a case study where results are obtained with both versions of the model. The results are compared for three different building types in two different locations.

The structure of this paper is as follows:

- $\quad$ section 2 introduces DER-CAM

- $\quad$ section 3 describes the new model of the TES and the storage loss estimation

- $\quad$ section 4 presents the data for the case study

- section 5 presents the result from the DER-CAM simulations, and

- $\quad$ section 6 discuss the results and concludes the paper.

\section{DER-CAM}

DER-CAM is a mixed-integer linear program (MILP) written in the General Algebraic Modeling System (GAMS) [22]. Its objective is to minimize the annual costs or $\mathrm{CO}_{2}$ emissions for providing energy services to the modeled site, including utility electricity and natural gas purchases, plus amortized capital and maintenance costs for any DER investments. The key inputs are customer loads, electricity and natural gas tariffs, and data of DER technologies, including capital and O\&M costs, conversion efficiency, heat-to-power ratio, maximum operating hours, among others. Key outputs include annual energy costs, the optimal onsite capacities, and dispatch of selected technologies and demand response measures, as well as passive measure investments (e.g. window replacements).

DER-CAM's earliest development goes back to 2000 [23], and simple stable versions can be accessed freely by the general public using a web interface [17]. Along with HOMER [24], formerly developed by the National Renewable Energy Laboratory, it is one of the few tools of its kind available for public use. DER-CAM has been continuously improved to incorporate new technologies and features, as reported in several peer-reviewed publications [25, 26]. Recently, it has also been updated to incorporate cold storage [27], stochastic EV modeling 
[28], as well as stochastic reliability issues [29]. It can also be applied to EV fleet scheduling [30].

Importantly, DER-CAM considers the interdependence of results. For instance, building cooling technologies will reflect the benefit of electricity demand displacement from possible heat-activated cooling, which can lower building peak loads and, therefore, the on-site generation or utility purchase requirement. Reduced on-peak usage also has a disproportionate benefit on bills because of demand charges and time-of-use (TOU) energy rates. For a more detailed description of the DER-CAM model see [22, 25, 31, 32].

\section{Figure 1: High level schematic of DER-CAM [33]}

Figure 1 shows a high-level schematic of building energy flows as modeled in DER-CAM. This Sankey diagram shows graphically how loads can be met by different resources at given efficiencies. Thus, a Sankey diagram provides a full view of possible resources considered within the optimization. Available energy inputs to the site are solar radiation, utility electricity, utility natural gas, biofuels, and geothermal heat. DER-CAM finds the optimal combination and operation of technologies to supply the services specified on the right-hand side of Figure 1 at each time step. Each arrow in Figure 1 represents an energy flow of some form (e.g. natural gas, electricity, waste heat) and DER-CAM optimizes these energy flows to minimize costs or $\mathrm{CO}_{2}$ emissions.

The most commonly used objective function within DER-CAM is to minimize the total energy cost according to (1),

$$
\min C_{\text {tot }}=C_{\text {elec }}+C_{D E R}+C_{f u e l}+C_{D R}+C_{\text {bat }}-\sum_{\mathrm{t}} V_{\mathrm{t}}
$$

where $C_{\text {elec }}$ is the electricity cost, $C_{D E R}$ is the amortized capital cost of DER equipment, $C_{\text {fuel }}$ is the fuel cost, $C_{D R}$ is the cost related to demand response, $C_{b a t}{ }^{1}$ is the EV battery degradation cost, and $V_{t}$ is the energy sales. As mentioned previously DER-CAM can also be used for $\mathrm{CO}_{2}$ minimization according to (2),

$$
\min \mathrm{CO}_{2 \text { tot }}=\mathrm{CO}_{2 \text { elec }}+\mathrm{CO}_{2 \text { fuel }}+\mathrm{CO}_{2 \mathrm{EV}}
$$

where $\mathrm{CO}_{2}$ elec is the $\mathrm{CO}_{2}$ emission from utility electricity consumption, $\mathrm{CO}_{2}$ fuel is the $\mathrm{CO}_{2}$ emission from fuel usage and $\mathrm{CO}_{2} \mathrm{EV}^{1}$ is the $\mathrm{CO}_{2}$ emission from charging of EVs. Because TES is both linked with loads and other DER technologies that consume electricity and natural gas, its performance will be interrelated to consumption of electricity, natural gas, as well as the total optimal capital costs for DER.

\section{New Thermal Energy Storage Model in DER-CAM}

The nature of different heat loads typically translates into different heat temperature requirements. For instance, to provide heat to absorption chillers the heat source temperature must be above an approximate $90^{\circ} \mathrm{C}$ minimum [34], while other heat loads such as space heating and domestic hot water may be served by heat sources at temperature levels around and below $65^{\circ} \mathrm{C}[35]$.

Similarly, different technologies will be able to provide heat at different temperatures, depending on their technical specifications. Micro-CHP units, for example, will be able to provide high temperature heat, while most heat pumps are only used to provide low temperature heat to achieve high coefficients of performance (COP) [36].

The temperature changes in storage tanks depend on the energy injected into/extracted from them, but also on their size, i.e. a large storage will experience a small increase in temperature compared to a small storage for the same injected energy. For investment and planning tools, both the size and usage of the TES are normally decision variables, hence temperature can't be directly tracked without creating an endogenous problem which can't be solved using a MILP solver. Thus, TES have historically been considered in DER-CAM as high temperature (HT) storage that can only be charged by equally high temperature technologies, and low temperature (LT) sources, such as heat pumps, could only be used to directly supply low temperature loads and without the ability to charge storage tanks. Further details on the previous TES model within DER-CAM can be found in [22].

To enable the use of LT technologies as heat sources to TES without explicitly tracing temperature, TES is now modeled by two individual temperature sections, namely LT and HT sections. The key is that the size of each section is a decision variable determined by DER-CAM. Each section is modeled as a stratified tank with two temperature strata. This approach adds further details to the TES modeling but does not require temperature

\footnotetext{
${ }^{1}$ Electric vehicles are not considered in this work.
} 
Modeling of thermal storage systems in MILP distributed energy resource models

Submitted to APPLIED ENERGY

tracking and therefore avoids the endogeneity problem previously mentioned.

In the improved model, TES can be charged by LT heat sources such as heat pumps, while maintaining the possibility of using the same tank for HT applications, via the HT section of the tank. Figure 2 presents a schematic of the TES model implemented in this work. Here, HT heat can be used both for HT and LT applications, including charging of the HT and/or LT section of the storage, while LT heat can only be used for LT applications, including charging of the LT section of the storage.

Figure 2: Schematic figure of the thermal energy storage with a high temperature (HT) and a low temperature (LT) section

The heat provided by all HT and LT sources is calculated according to (3) and (4),

$$
\begin{gathered}
H_{\mathrm{t}, \mathrm{k}}^{\text {prov }}=H_{\mathrm{t}}^{\text {CHP }}+H_{\mathrm{t}}^{\text {Solar }}+H_{\mathrm{t}}^{N G}+H_{\mathrm{t}}^{\text {NG chill rec }}+H_{\mathrm{t}, \mathrm{k}}^{\text {from TES }} \forall \mathrm{t}, \mathrm{k}=\mathrm{HT} \\
H_{\mathrm{t}, \mathrm{k}}^{\text {prov }}=H_{\mathrm{t}}^{\text {ASHP }}+H_{\mathrm{t}}^{\text {GSHP }}+H_{\mathrm{t}, \mathrm{k}}^{\text {from TES }}+H_{\mathrm{t}}^{\text {HT prov for } L T} \forall \mathrm{t}, \mathrm{k}=\mathrm{LT}
\end{gathered}
$$

where $H_{\mathrm{t}, \mathrm{k}}^{\text {from TES }}$ is the useful heat supplied, i.e. heat taken from TES, minus losses due to the discharge efficiency, as shown in Figure 2. The overall heat consumption is calculated according to (5) and (6),

$$
\begin{aligned}
& H_{\mathrm{t}, \mathrm{k}}^{\text {cons }}=H_{\mathrm{t}}^{\text {cooling }}+H_{\mathrm{t}}^{\text {refrig }}+H_{\mathrm{t}, \mathrm{k}}^{\text {for TES }}+H_{\mathrm{t}}^{\text {HT prov for } L T} \forall \mathrm{t}, \mathrm{k}=\mathrm{HT} \\
& H_{\mathrm{t}, \mathrm{k}}^{\text {cons }}=H_{\mathrm{t}}^{\text {space }}+H_{\mathrm{t}}^{\text {water }}+H_{\mathrm{t}}^{\text {for TES }} \forall \mathrm{t}, \mathrm{k}=\mathrm{LT}
\end{aligned}
$$

where $H_{\mathrm{t}, \mathrm{k}}^{\text {for TES }}$ is the heat used to charge the HT/LT section of TES. Similar to the discharge process, there are losses associated with the charge process, as shown in Figure 2.

To maintain the heat balance, equation (7) ensures that the heat provided is equal to the heat consumed, which is valid for both HT and LT, and considers both sections of the TES.

$$
H_{\mathrm{t}, \mathrm{k}}^{\text {prov }}=H_{\mathrm{t}, \mathrm{k}}^{\text {cons }} \forall \mathrm{t}, \mathrm{k}
$$

The energy that is stored in each calculation step in both the LT and HT section is calculated according to (8), stating that the energy stored in any given time step is equal to the energy that was stored in the previous time step, plus energy inputs, and minus output that can result either from discharging or losses,

$$
H_{\mathrm{t}}^{\text {stored }}=H_{\mathrm{t}-1, \mathrm{k}}^{\text {stored }}+\eta_{\mathrm{ch}, \mathrm{k}} \cdot H_{\mathrm{t}, \mathrm{k}}^{\text {for TES }}-\frac{H_{t}^{\text {from TES }}}{\eta_{\mathrm{disch}, \mathrm{k}}}-\operatorname{LosS}_{\mathrm{t}, \mathrm{k}}^{T E S} \forall \mathrm{t}, \mathrm{k}
$$

where $\operatorname{Loss}_{\mathrm{t}, \mathrm{k}}^{T E S}$ represent heat losses that occur depending on the amount of energy stored in the TES, the capacity of the TES and ambient temperature. These losses are calculated according to (9),

$$
\operatorname{Loss}_{t, k}^{T E S}=H_{t-1, k}^{\text {stored }} \cdot \theta_{\mathrm{k}}^{\text {storage }}+\theta_{\mathrm{k}}^{\text {static }} \cdot E_{t, k}^{\text {unuse }} \forall \mathrm{t}, \mathrm{k}
$$

where $\theta_{\mathrm{k}}^{\text {storage }}$ is the loss coefficients for the HT/LT section related to the losses based on the energy stored in the storage and $\theta_{\mathrm{k}}^{\text {static }}$ is the static loss coefficients related to the losses occurring when the temperature inside the storage is at the minimum usable temperature, represented as $E_{k}^{\text {unuse }}$ which is calculated according to (19) in section 3.1 .

The key investment decision made by DER-CAM regarding TES is the installed capacity, equal to the sum of HT and LT section capacities, which are also decision variables (10).

$$
\text { Cap } \text { storage }^{=} \sum_{\mathrm{k}=\mathrm{LT}}^{H T} \operatorname{Cap}_{\mathrm{k}}
$$

The energy content stored in each of these sections is limited by their individual capacity, according to (11).

$$
H_{\mathrm{t}, \mathrm{k}}^{\text {stored }} \leq \operatorname{Cap}_{\mathrm{k}} \forall \mathrm{t}, \mathrm{k}
$$

In each section, the energy output is limited by a discharge rate, and is calculated according to (12).

$$
\frac{H_{t}^{\text {from TES }}}{\eta_{\text {disch, } \mathrm{k}}} \leq \operatorname{Cap}_{\mathrm{k}} \cdot \max _{\mathrm{k}}^{\text {disch. rate }} \forall \mathrm{t}, \mathrm{k}
$$

Likewise, the input energy to storage is limited by a maximum charge rate, which is expressed by (13).

$\eta_{\mathrm{ch}, \mathrm{k}} \cdot H_{\mathrm{t}, \mathrm{k}}^{\text {for TES }} \leq \operatorname{Cap}_{\mathrm{k}} \cdot \max _{\mathrm{k}}^{\mathrm{ch} .}$ rate $\forall \mathrm{t}, \mathrm{k}$ 
Modeling of thermal storage systems in MILP distributed energy resource models Submitted to APPLIED ENERGY

\subsection{Estimation of storage losses}

In order to better understand how the TES losses are modeled in DER-CAM, both the previous and improved DER-CAM TES loss calculation methods are explained and compared to losses in a fully mixed, i.e. with a uniform temperature profile inside the tank, and ideal stratified heat storage tank.

In a real TES the stratification is not perfect due to mixing of water during charge-discharge cycles and due to conduction through water and walls in the tank, meaning that the losses from a real TES would be somewhere in between the fully mixed and ideally stratified cases based on [15].

The storage losses in a fully mixed TES can be calculated according to (14),

$$
\text { Loss }=\Delta T \cdot U \cdot A
$$

where $\Delta \mathrm{T}$ is the difference between the uniform water temperature inside the storage and the ambient temperature, $\mathrm{U}$ is the overall heat transfer coefficient of the storage tank, and $\mathrm{A}$ is its surface area.

Figure 3 presents the losses for different sizes and storage temperature (i.e. charge levels) of a fully mixed TES, calculated according to (14) using the commercial software package Matlab [37]. The height of this storage tank is considered to be fixed at $2 \mathrm{~m}$ and only the radius is changing with storage size. The loss calculations are made assuming an ambient temperature of $21^{\circ} \mathrm{C}$ and a U-value of $0.5 \mathrm{~W} / \mathrm{m} 2 \mathrm{~K}$ (i.e. about $0.1 \mathrm{~m}$ of mineral wool insulation).

As illustrated, losses increase with the storage tank size, due to the increased surface area. Furthermore, since the ambient temperature is lower than the minimum TES usable temperature, assumed to be $65^{\circ} \mathrm{C}$ for the $\mathrm{HT}$ section, heat losses always occur regardless of the charge level.

Figure 3: Storage losses for a fully mixed TES calculated for different storage sizes and charge levels, $65^{\circ} \mathrm{C}$ represents $0 \%$ SOC and $90^{\circ}$ C represents 100\% SOC, based on equation (14) using Matlab

Figure 4 Storage losses for an ideal stratified TES calculated for different storage sizes and charge levels, based on (15) using Matlab

For a TES with ideal stratification, i.e. two perfectly defined and independent temperature levels (i.e. $\mathrm{T}^{\mathrm{max}}$ $\left(90^{\circ} \mathrm{C}\right)$ and $\mathrm{T}^{\mathrm{min}}\left(65^{\circ} \mathrm{C}\right)$ ) separated by the thermocline zone within the tank, losses can be derived according to equation (15) [7].

$$
\text { Loss }=\left(\mathrm{T}^{\mathrm{min}}-\mathrm{T}^{\mathrm{amb}}\right) \cdot\left(\mathrm{P} \cdot \mathrm{X}+\mathrm{r}^{2} \pi\right) \cdot \mathrm{U}+\left(\mathrm{T}^{\mathrm{max}}-\mathrm{T}^{\mathrm{amb}}\right) \cdot\left(\mathrm{P} \cdot(\mathrm{H}-\mathrm{X})+\mathrm{r}^{2} \pi\right)
$$

where, $\mathrm{P}$ is the TES external perimeter, $\mathrm{X}$ is the position of the thermocline level from the bottom of the tank (which varies with the state of charge), $\mathrm{H}$ and $\mathrm{r}$ are the TES height and radius of the TES. Figure 4 presents the losses for an ideal stratified TES with the same assumptions used for the fully mixed TES, but calculated according to (15). Since the height of the TES is kept fixed, the top and bottom area of the storage tank increase with the storage size. However, since the temperature at the top and bottom of the tank is constant for an ideal stratified TES, the storage losses will be less dependent on the actual charge level for large TES compared to the fully mixed TES. With a better storage design, e.g. increased height for large TES, the influence of the tank radius can be reduced. As illustrated by Figure 3 and Figure 4, the ideal stratified tank will have higher losses for low charge levels and lower losses for high charge levels compared to the fully mixed storage.

Figure 5: Storage losses, estimated by the previous TES model in DER-CAM, for different storage sizes and charge levels, based on (16) using Matlab

The previous DER-CAM TES model estimated storage losses as a percentage $\left(\theta_{\mathrm{k}}^{\text {storage }}\right)$ of the energy stored in the TES according to (16).

$$
\operatorname{Loss}_{\mathrm{t}, \mathrm{k}}=H_{\mathrm{t}-1, \mathrm{k}}^{\text {stored }} \cdot \theta_{\mathrm{k}}^{\text {storage }} \forall \mathrm{t}, \mathrm{k}=\mathrm{HT}
$$

Figure 5 presents the losses for different storage sizes and charge levels as estimated by that version, with the loss coefficient $\left(\theta_{\mathrm{k}}^{\text {storage }}\right)$ equal to $1 \%$. As seen in Figure 5 , whenever there is no usable energy stored, i.e. when the temperature inside the tank is at the minimum temperature $\left(65^{\circ} \mathrm{C}\right)$, no storage losses occurs. Furthermore, storage losses increase rapidly as the tank becomes charged in the old model.

In the improved model the storage losses are still estimated based on the energy content inside the tank, but a static part is added to the model. Also, the improved model takes into account the ambient temperature based on the equations presented below. The static part is calculated as a percentage $\left(\theta_{\mathrm{k}}^{\text {static }}\right)$ of the unusable energy that is stored when the temperature drops below the minimum temperature, which is calculated according to (17), 
Modeling of thermal storage systems in MILP distributed energy resource models Submitted to APPLIED ENERGY

$E_{\mathrm{t}, \mathrm{k}}^{\text {unuse }}=\mathrm{cp} \cdot \rho \cdot \mathrm{V}_{\mathrm{k}} \cdot\left(\mathrm{T}_{\mathrm{k}}^{\min }-\mathrm{T}_{\mathrm{t}}^{\mathrm{amb}}\right)$

where the storage volume is calculated according to (18).

$V_{\mathrm{k}}=\frac{C a p_{\mathrm{k}}}{\rho \cdot \mathrm{cp} \cdot\left(\mathrm{T}_{\mathrm{k}}^{\max }-\mathrm{T}_{\mathrm{k}}^{\min }\right)}$

By replacing $V_{k}$ in (17) with (18) the unused energy can be calculated based on the capacity of the storage, the ambient temperature and the minimum and maximum temperatures of the storage according to (19).

$$
E_{\mathrm{t}, \mathrm{k}}^{\text {unuse }}=\operatorname{Cap}_{\mathrm{k}} \cdot \frac{\left(\mathrm{T}_{\mathrm{k}}^{\mathrm{min}}-\mathrm{T}_{\mathrm{t}}^{\mathrm{amb}}\right)}{\left(\mathrm{T}_{\mathrm{k}}^{\mathrm{max}}-\mathrm{T}_{\mathrm{k}}^{\min }\right)}
$$

By combining the heat losses based on the energy stored in the storage, i.e. equation (16), with the losses associated with the unusable energy calculated from (19), the total storage losses for the LT/HT section can be estimated according to (9). Figure 6 presents the storage losses, for the HT section, estimated by the improved TES model now implemented in DER-CAM, with the loss coefficient $\left(\theta_{\mathrm{k}}^{\text {storage }}\right)$ equal to $0.060 \%$ and the static loss coefficient $\left(\theta_{\mathrm{k}}^{\text {static }}\right)$ equal to $0.053 \%$. The coefficients were found by iteratively varying the coefficients so that the estimated losses roughly match the losses of a fully mixed TES presented in Figure 3. Nonetheless, the loss coefficients $\left(\theta_{\mathrm{k}}^{\text {storage }}\right.$ and $\left.\theta_{\mathrm{k}}^{\text {static }}\right)$ can be varied to represent TES with other characteristics, e.g. less insulation or better stratification. As can be seen in Figure 3, the losses are slightly overestimated for small TES and slightly underestimated for large TES. Hence, the accuracy of the improved TES model depends on the actual TES size decided by DER-CAM.

Figure 6: Storage losses, estimated by the improved DER-CAM TES model, for different storage sizes and charge levels, based on (9) using Matlab

TABLE 1 LOAD DATA FOR THE BUILDINGS AND SITES IN THE CASE STUDY, [38]

\section{Case Study}

This section presents the most relevant data used in the case study where both the previous and improved DER-CAM TES models are compared. The load data is based on the California Commercial End Use Survey (CEUS) [38]. Three different building types were analyzed - a large college building (LCOLL), a large health care facility (LHLTH), and a large hotel (LHOT), each assumed to be located in both San Francisco and San Diego, California. The warmer climate in San Diego compared to San Francisco results in a higher cooling demand, whereas the heating demand for buildings in San Francisco is higher compared to San Diego. The annual energy demand for each building and load type is presented in Table 1.

The reason for choosing two different locations is to allow comparing results not only in different climates but also with different electricity and natural gas tariffs, which affects the economics of TES [27]. The electricity and natural gas tariffs used in the case study are presented in Table 2 and are taken from [39].

TABLE 2 ELECTRICITY AND NATURAL GAS TARIFFS FOR ALL LOCATIONS AND BUILDINGS, [39]

TABLE 3 INVESTMENT COSTS FOR STORAGE, RENEWABLE, AND ELECTRIC TECHNOLOGIES, [39]²-[40]

TABLE 4 INVESTMENT COST FOR NATURAL GAS FIRED TECHNOLOGIES, [39 $]^{3}$

The key data regarding all possible technology investments used in this case study are presented in Table 3 and Table 4, which is further described in [39]. The data for heat pumps is based on EIA's technology forecast in [40]. Since one of the main differences introduced in the improved TES model is its possibility to store heat from heat pumps in the LT TES section, two different sets of runs are conducted, both with and without heat pumps available.

The data used for the TES is presented in Table 5. The parameters used for the previous heat storage is based on [41], while the loss coefficients for the improved storage are found to match a fully mixed storage. The assigned temperature levels are based on [21] and [36] to enable the use of HP and absorption chillers.

\footnotetext{
${ }^{2}$ Costs are assumed to be for the year 2020.

${ }^{3}$ Costs are assumed to be for the year 2020.
} 
Modeling of thermal storage systems in MILP distributed energy resource models Submitted to APPLIED ENERGY

TABLE 5 PARAMETERS USED FOR BOTH TES MODELS

For all simulations, the optimality gap was set to 0.05 for the CPLEX solver.

\section{Results}

This section compares the key results obtained with both TES models for the buildings described in Table 1 . Under the assumptions used, TES adoption is not strongly economically attractive in cost minimization runs. The reason is due to the large number of technologies available, other technology combinations crowd out TES deployment in the cost minimization runs. Consequently, the results presented here focus on $\mathrm{CO}_{2}$ minimization runs, as they produce higher TES adoption rates, and therefore provide a better understanding of the improved TES model impact.

Table 6 presents the relative changes $(\%)$ in optimal technology investments obtained using the improved TES model against results from the previous model, considering $\mathrm{CO}_{2}$ minimization and without heat pumps. In this case, the previous model suggests more TES investments in five of six buildings by 5-100\% compared to the improved model. For two buildings in San Francisco, no TES is adopted with the improved model and a decrease in heat providing technologies, i.e. CHP and solar thermal, is observed. For one building (large college) in San Diego, the TES investment increases by $158 \%$ for the improved model and investments are shifted from DG without HX to CHP.

\section{TABLE 6 CHANGE IN OPTIMAL TECHNOLOGY INVESTMENT COMPARED TO THE PREVIOUS VERSION OF DER-CAM, WITHOUT HP, $\mathrm{CO}_{2}$ MINIMIZATION}

Although DER-CAM can decide freely on the size of the HT and LT sections, results indicate a clear tendency towards the latter, driven by higher losses associated with the HT section. In Table 6 the HT and LT sections are compared to the entire TES investment in the previous model and, as can be seen, for all optimization runs, all TES investments for the HT section are zero.

Table 7 presents the results obtained in the $\mathrm{CO}_{2}$ minimization case with heat pump investments enabled. In this case the improved model produce between 14-68\% more heat storage for buildings in San Diego compared to the previous model. For San Francisco, the improved model produces a decrease in heat storage and for two buildings no TES were adopted with the improved model. Although it is possible to store heat from HP with the improved TES model, it does not seem to motivate investments in either TES or heat pumps to decrease $\mathrm{CO}_{2}$ emissions for the investigated buildings in San Francisco while the opposite holds for San Diego.

Analyzing results in greater detail, total investments in heat pumps (ASHPs and GSHPs) increase in the improved model for all San Diego buildings, while they decrease for all San Francisco buildings. It is likely that the increased investment in heat pump in San Diego is due to the possibility to store heat from heat pumps in the LT storage section. Similarly to the HP-disabled optimization runs, all TES investments show no HT section. Since only absorption chiller requires HT heat, this result shows that with the improved model the heat used for absorption chiller in the investigated sites is provided directly from the HT heat providing technologies, e.g. CHP units and solar thermal. For other locations or under other assumptions (e.g. without possibility to invest in CHPs) the need to store HT heat might change.

Despite the widely different capacities of adopted technologies, the variations observed in the total annual $\mathrm{CO}_{2}$ emissions are roughly between $4 \%$ and $-3 \%$, with the exception of the college building in San Francisco where a 7-9\% difference was observed. This suggests that the improved TES model may have a relevant impact on optimal technology selection, but due to the large number of technologies available, the objective function values stay very stable, demonstrating the complexity of such a DER optimization problem. These optimization problems involve searching over a very large and nearly flat solution space.

TABLE 7 CHANGE IN OPTIMAL TECHNOLOGY INVESTMENT COMPARED TO PREVIOUS VERSION OF DER-CAM, WITH $\mathrm{HP}, \mathrm{CO}_{2}$ MINIMIZATION

\subsection{Fixed thermal energy storage}

To further compare the usage of TES between the two models, a forced investment run for a TES of $2,000 \mathrm{kWh}$ was performed. This means that a 2,000 $\mathrm{kWh}$ TES is forced into the DER investment solution obtained by each model, but DER-CAM is still allowed to decide on TES usage and dispatch as well as the division between HT and LT section. These runs allow all DER options available (including HPs) and Figure 7 presents the energy stored in the TES together with the storage losses in the storage for a typical weekday in March for the large San Diego hotel building. 
Both models use storage in a similar fashion, although the improved TES model store the energy for long periods of time compared to the previous model. Regarding losses, the improved model presents lower losses compared to the previous one, except for the hours when the storage is empty, which is directly tied to the limitations in the previous model. This is also the reason why the energy is stored for a longer period of time with the improved model.

Although DER-CAM decides to invest in both heat pumps and absorption chillers, only LT TES is chosen, although it has the possibility to invest in HT TES. This indicates that, for this building, it is more beneficial to use the TES to store heat from heat pumps than to use it with absorption chillers, since the losses associated with the LT section of the TES are lower compared to the HT section.

Over a time horizon of one year, the storage losses, not including losses from charge-discharge efficiencies, obtained using the improved model result in roughly $2 \%$ of the annual energy taken from the TES, against roughly $7 \%$ obtained in the previous version of the TES model. The reason for the low losses in the improved model is due to that only LT TES are utilized, and that a low U-value has been assumed when estimating the loss coefficients.

Figure 7: Energy stored in the TES and the estimated storage losses for both TES models for building LHOT in San Diego for a weekday in March

Figure 8 presents the average energy taken from TES for weekday and weekend day-types each month, for both the previous and improved models. As observed in this figure, the amount of energy taken from the 2000 KWh storage has increased in the improved TES model during summer, while it stayed at the same levels during winter.

\section{Figure 8: Energy taken from storage for both TES models for building LCOLL in San Francisco for weekdays and weekends in January}

Although TES losses are reduced in the improved model, these losses are only one part of the total losses associated with storage. In fact, most losses are due to the TES charging and discharging efficiencies. In the case study runs, these losses have been assumed to be $10 \%$ of the energy supplied or taken from TES, and for that reason, storage losses are small in comparison to charging-discharging losses. This suggests that follow-up research needs to address the charging-discharging efficiencies in an extended model.

\section{Conclusions and Further Work}

This paper presents an improved TES model implemented in DER-CAM version 4.0.0. The adopted formulation consists of modeling TES with two different temperature sections, one high temperature and one low, to enable the possibility of charging the TES with low temperature providing technologies, such as heat pumps in addition to high temperature providing technologies like CHP. Additionally, the accuracy of the estimated storage losses within TES has been improved to better match a real TES. This model avoids endogenous optimization problems and allows investment decisions paired with operational optimization in MILP formulations.

A case study of three different buildings in two California cities with different climates and utility tariffs was performed to compare the improved model with its predecessor. Results when heat pumps were not available indicate a decrease in TES investments using the improved model for most buildings analyzed. However, with the possibility to invest in heat pumps, the TES investments increase for all buildings in San Diego. At the same time, investments in heat pumps increase for these buildings. Furthermore, for most buildings, the result shows only a minor difference in the objective function and the $\mathrm{CO}_{2}$ emissions only differ minimally, although the technology selection differs widely between the models. This highlights the overall complexity of DER sizing problems and the added complexity of the improved TES model, as well as the relatively flat solution space found in these problems. It is also important to note that the case study only involves three building types at two different locations, the result may differ for other locations and available technologies.

For all locations and buildings analyzed in the case study, results show that the previous model estimates higher storage losses. Furthermore, the improved model shows that the heat is stored in TES for longer periods of time compared to the previous model. However, due to the charge-discharge losses associated with the TES, this does not have a great impact on objective function values and follow-up research needs to address the charging and discharging efficiencies. As discussed in the paper, a TES model based on the second law of thermodynamic couldn't be integrated in DER-CAM due to the endogenous problem formulation. However, it would be interesting to compare the accuracy of the results from the improved TES model with a more detailed 
Modeling of thermal storage systems in MILP distributed energy resource models Submitted to APPLIED ENERGY

TES model considering the second law of thermodynamic. Furthermore, as the cost for latent TES decreases, it becomes more competitive, especially for sites with space limitation. Including latent heat storages into the set of technologies available in DER-CAM could also be useful, both when finding the optimal DER mix but also to assess at which cost these storages are becoming economically feasible.

\section{Acknowledgements}

DER-CAM has been funded partly by the Office of Electricity Delivery and Energy Reliability, Distributed Energy Program of the U.S. Department of Energy under Contract No. DE-AC02-05CH11231. The Distributed Energy Resources Customer Adoption Model (DER-CAM) has been designed at Lawrence Berkeley National Laboratory (LBNL). Furthermore, Chalmers Energy Initiative is greatly acknowledged for funding D. Steen's guest research visit to Lawrence Berkeley National Laboratory.

\section{References}

[1] M. T. Miller, M. B. Johns, E. Sortomme, and S. S. Venkata, "Advanced integration of distributed energy resources," in Power and Energy Society General Meeting, 2012 IEEE, 2012, pp. 1-2.

[2] M. F. Akorede, H. Hizam, and E. Pouresmaeil, "Distributed energy resources and benefits to the environment," Renewable and Sustainable Energy Reviews, vol. 14, pp. 724-734, 2// 2010.

[3] R. Poudineh and T. Jamasb, "Distributed generation, storage, demand response and energy efficiency as alternatives to grid capacity enhancement," Energy Policy.

[4] R. Arghandeh, A. Onen, J. Jung, and R. P. Broadwater, "Harmonic interactions of multiple distributed energy resources in power distribution networks," Electric Power Systems Research, vol. 105, pp. 124$133,12 / / 2013$.

[5] M. Beaudin, H. Zareipour, A. Schellenberglabe, and W. Rosehart, "Energy storage for mitigating the variability of renewable electricity sources: An updated review," Energy for Sustainable Development, vol. 14, pp. 302-314, 12// 2010.

[6] N. Altuntop, M. Arslan, V. Ozceyhan, and M. Kanoglu, "Effect of obstacles on thermal stratification in hot water storage tanks," Applied Thermal Engineering, vol. 25, pp. 2285-2298, 10// 2005.

[7] A. Campos Celador, M. Odriozola, and J. M. Sala, "Implications of the modelling of stratified hot water storage tanks in the simulation of CHP plants," Energy Conversion and Management, vol. 52, pp. 3018$3026,8 / / 2011$.

[8] P. Tatsidjodoung, N. Le Pierrès, and L. Luo, "A review of potential materials for thermal energy storage in building applications," Renewable and Sustainable Energy Reviews, vol. 18, pp. 327-349, 2// 2013.

[9] K. H. Khan, M. G. Rasul, and M. M. K. Khan, "Energy conservation in buildings: cogeneration and cogeneration coupled with thermal energy storage," Applied Energy, vol. 77, pp. 15-34, 1// 2004.

[10] A. D. Smith, P. J. Mago, and N. Fumo, "Benefits of thermal energy storage option combined with CHP system for different commercial building types," Sustainable Energy Technologies and Assessments, vol. 1, pp. 3-12, 3// 2013.

[11] A. Sharma, V. V. Tyagi, C. R. Chen, and D. Buddhi, "Review on thermal energy storage with phase change materials and applications," Renewable and Sustainable Energy Reviews, vol. 13, pp. 318-345, 2// 2009.

[12] M. Noro, R. M. Lazzarin, and F. Busato, "Solar cooling and heating plants: An energy and economic analysis of liquid sensible vs phase change material (PCM) heat storage," International Journal of Refrigeration.

[13] B. Zalba, J. M. Marín, L. F. Cabeza, and H. Mehling, "Review on thermal energy storage with phase change: materials, heat transfer analysis and applications," Applied Thermal Engineering, vol. 23, pp. 251-283, 2// 2003.

[14] M. K. Rathod and J. Banerjee, "Thermal stability of phase change materials used in latent heat energy storage systems: A review," Renewable and Sustainable Energy Reviews, vol. 18, pp. 246-258, 2// 2013.

[15] V. Badescu, "Optimal operation of thermal energy storage units based on stratified and fully mixed water tanks," Applied Thermal Engineering, vol. 24, pp. 2101-2116, 10// 2004.

[16] R. J. Krane, "A Second Law analysis of the optimum design and operation of thermal energy storage systems," International Journal of Heat and Mass Transfer, vol. 30, pp. 43-57, 1// 1987.

[17] (31 october). DER-CAM website. Available: http://building-microgrid.lbl.gov/

[18] M. Heidari Tari and M. Söderström, "Modelling of thermal energy storage in industrial energy systems the method development of MIND," Applied Thermal Engineering, vol. 22, pp. 1195-1205, 8// 2002.

[19] M. A. Lozano, J. C. Ramos, and L. M. Serra, "Cost optimization of the design of CHCP (combined 
[20] H. Ren and W. Gao, "A MILP model for integrated plan and evaluation of distributed energy systems," Applied Energy, vol. 87, pp. 1001-1014, 3// 2010.

[21] J. Labus, J. C. Bruno, and A. Coronas, "Performance analysis of small capacity absorption chillers by using different modeling methods," Applied Thermal Engineering, vol. 58, pp. 305-313, 9// 2013.

[22] M. Stadler, C. Marnay, A. Siddiqui, J. Lai, B. Coffey, and H. Aki, "Effect of Heat and Electricity Storage and Reliability on Microgrid Viability: A Study of Commercial Buildings in California and New York States," LBNL LBNL - 1334E, 2008.

[23] C. Marnay, R. Blanco, K. S. Hamachi, C. P. Kawaan, J. G. Osborn, and F. J. Rubio, "Integrated assessment of dispersed energy resources deployment," LBNL-46082, 2000.

[24] (31 October). Homer Energy website. Available: http://www.homerenergy.com/

[25] M. Stadler, A. Siddiqui, C. Marnay, H. Aki, and J. Lai, "Control of Greenhouse Gas Emissions by Optimal DER Technology Investment and Energy Management in Zero-Net-Energy Buildings," European Transactions on Electrical Power 2010, Special Issue on Microgrids and Energy Management, vol. 21, 2010.

[26] A. S. Siddiqui, C. Marnay, J. L. Edwards, R. Firestone, S. Ghosh, and M. Stadler, "Effects of carbon tax on microgrid combined heat and power adoption," Journal of Energy Engineering-Asce, vol. 131, pp. 225, Apr 2005.

[27] N. DeForest, G. Mendes, M. Stadler, W. Feng, J. Lai, and C. Marnay, "Optimal deployment of thermal energy storage under diverse economic and climate conditions," Applied Energy vol. in press., 2014.

[28] G. Cardoso, M. Stadler, M. Chehreghani Bozchalui, R. Sharma, C. Marnay, A. Barbosa-Póvoa, and P. Ferrão, "Stochastic Programming of Vehicle to Building Interactions with Uncertainty in PEVs Driving for a Medium Office Building," in IEEE IECON, Vienna, Austria, , 2013.

[29] G. Cardoso, M. Stadler, A. Siddiqui, C. Marnay, N. DeForest, A. Barbosa-Póvoa, and P. Ferrão, "Microgrid reliability modeling and battery scheduling using stochastic linear programming," Electric Power Systems Research, vol. 103, pp. 61-69, 10// 2013.

[30] C. Marnay, T. Chan, N. DeForest, J. Lai, J. MacDonald, M. Stadler, T. Erdmann, A. Hoheisel, M. Müller, S. Sabre, E. Koch, P. Lipkin, R. W. Anderson, S. Gerber, and E. Reid, "Los Angeles Air Force Base Vehicle to Grid Pilot Project," presented at the European Council on an Energy Efficient Economy 2013 Summer Study, Club Belambra Les Criques, Presqu'île de Giens, Toulon/Hyères, France, 2013.

[31] M. Stadler, C. Marnay, G. Cardoso, T. Lipman, O. Mégel, S. Ganguly, A. Siddiqui, and J. Lai, "The CO2 Abatement Potential of California's Mid-Sized Commercial Buildings," LBNL-3024E, 2009.

[32] C. Marnay, G. Venkataramanan, M. Stadler, A. Siddiqui, R. Firestone, and B. Chandran, "Optimal Technology Selection and Operation of Microgrids in Commercial Buildings," IEEE Transactions on Power Systems, vol. 23, Aug 2008.

[33] M. Stadler, M. Kloess, M. Groissböck, G. Cardoso, R. Sharma, M. C. Bozchalui, and C. Marnay, "Electric storage in California's commercial buildings," Applied Energy, vol. 104, pp. 711-722, 4// 2013.

[34] J. Labus, J. A. Hernández, J. C. Bruno, and A. Coronas, "Inverse neural network based control strategy for absorption chillers," Renewable Energy, vol. 39, pp. 471-482, 2012.

[35] R. P. Wilson Jr, "Energy conservation options for residential water heaters," Energy, vol. 3, pp. 149$172,41978$.

[36] A. Hepbasli and Y. Kalinci, "A review of heat pump water heating systems," Renewable and Sustainable Energy Reviews, vol. 13, pp. 1211-1229, 8// 2009.

[37] "MATLAB release 2011a," ed: The MathWorks, Inc., Natick, Massachusetts, United States.

[38] (31 October). CEUS on the web. Available: http://capabilities.itron.com/ceusweb/

[39] M. Stadler, M. Groissböck, G. Cardoso, A. Müller, and J. Lai, "Encouraging Combined Heat and Power in California Buildings," Ernest Orlando Lawrence Berkeley National Laboratory LBNL-6267E, 2013.

[40] U.S. Energy Information Administration, "Updated Buildings Sector Appliance and Equipment Costs and Efficiency " Navigant Consulting, Inc.2013.

[41] M. Stadler, H. Aki, R. Firestone, J. Lai, C. Marnay, and A. Siddiqui, "Distributed energy resources onsite optimization for commercial buildings with electric and thermal storage technologies," presented at the ACEEE Summer Study on Energy Efficiency in Buildings, Pacific Grove, California, 2008. 


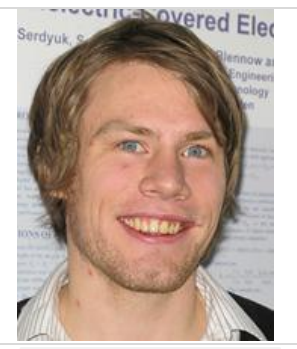

David Steen is currently pursuing the Ph.D. degree in electrical engineering from the Department of Energy and Environment at Chalmers University of Technology. He received the M.Sc. degree in 2008 in electrical engineering from Chalmers University of Technology, Gothenburg, Sweden and spent a research internship with Berkeley Lab in 2013. His main research interests are focused on planning and operation of the electrical distribution system, including load management strategies, electric vehicle charging.

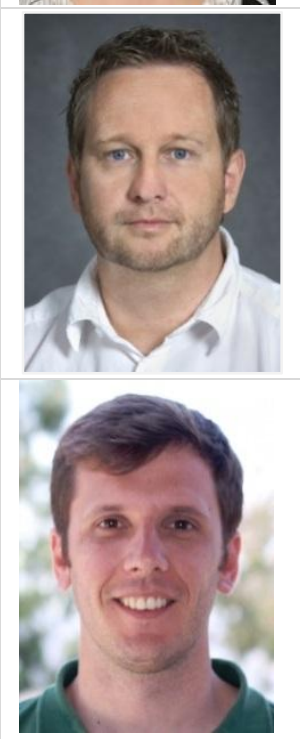

Michael Stadler is a Research Scientist at Lawrence Berkeley National Laboratory, California, USA. He studied at the Vienna University of Technology, from which he holds a Master's degree in electrical engineering and a Ph.D. summa cum laude in energy economics. He leads the microgrid and distributed energy resources team at Berkeley Lab and is the lead developer of DER-CAM. He is also the founder of the Center for Energy and innovative Technologies (CET) in Austria. Michael has published more than 160 papers, journal papers, reports, as well as five software tools in his 13 year career to date

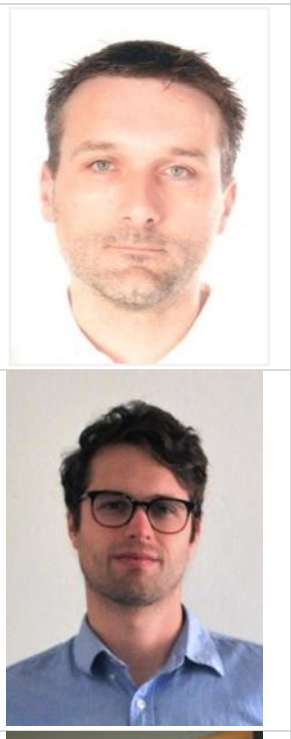

Gonçalo Cardoso is a Postdoctoral Fellow at the Lawrence Berkeley National Laboratory working for the Grid Integration Group of the Energy Storage and Distributed Resources Department. He received a M.Sc. in Civil Engineering from Instituto Superior Técnico, Technical University of Lisbon, Portugal, and later Ph.D. in Sustainable Energy Systems also from Instituto Superior Técnico within the MIT-Portugal Program. He focuses on Distributed Energy Resources Investment and Planning, having worked with DER-CAM since 2009, where he had several contributions including the implementation of stochastic capabilities, electric vehicle fleet modeling, critical loads, heat pumps, investment subsidies and feed-in tariffs within the California Self Generation Incentive Program, among others.

Markus Groissböck received the B.A. in European energy economics from the University of Applied Sciences, Kufstein, Austria. He received his M.S. degree in sustainable energy resources from the University of Applied Sciences, Burgenland, Austria. He was a Researcher with CET and the Ernest Orlando Lawrence Berkeley National Laboratory. His research interests lie in medium- and long-term investment planning within the energy sector and in designing user-friendly interfaces.

Nicholas DeForest is a Principal Research Associate in the Grid Integration Group (GIG) of the Energy Storage and Distributed Resources Department (ESDRD), where he works as a core developer for the optimization tool DER-CAM. His research focuses on using optimization to inform investment and operations decision-making for Distributed Energy Resources (DER). He received a M.S. degree in mechanical engineering from the University of California - Berkeley in 2009 and a B.S. degree in mechanical engineering from the University of Illinois - Urbana Champaign in 2007. He has been employed at LBNL since June 2010.

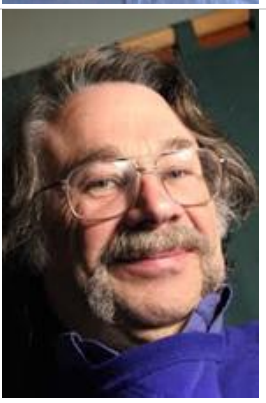

Chris Marnay is a retired Staff Scientist of the Grid Integration Group (GIG) of the Energy Storage and Distributed Resources Department, within the Environmental Energy Technologies Division. He worked at Berkeley Lab for 29 years, latterly modeling economic-environmental problems related to likely future deployment of microgrids exercising local semiautonomous control and able to island. He was an early member of the Consortium of Electric Reliability Solutions (CERTS) team that led to development of the DER-CAM. He chairs the annual International Microgrids Symposiums, and is the Convenor of CIGRÉ Working Group 6.22, Microgrid Evolution Roadmap. He has an A.B. in Development Studies, an M.S. in Agricultural and Resource Economics, and a Ph.D. in Energy and Resources, all from the University of California, Berkeley. 
Modeling of thermal storage systems in MILP distributed energy resource models Submitted to APPLIED ENERGY

\section{5 \\ Appendix A.1. Change in technology investment}

626

627

628

TABLE 8 TECHNOLOGY INVESTMENT IN IMPROVED AND PREVIOUS MODEL, WITHOUT POSSIBILITY TO INVEST IN HP

629

TABLE 9 TECHNOLOGY INVESTMENT IN IMPROVED AND PREVIOUS MODEL, WITH POSSIBILITY TO INVEST IN HP 


\section{Figure captions}

Figure 1: High level schematic of DER-CAM [30]

Figure 2: Schematic figure of the thermal energy storage with a high temperature (HT) and a low temperature (LT) section

Figure 3: Storage losses for a fully mixed TES calculated for different storage sizes and charge levels, $65^{\circ} \mathrm{C}$ represents $0 \%$ SOC and $90^{\circ} \mathrm{C}$ represents 100\% SOC, based on equation (14) using Matlab

Figure 4 Storage losses for an ideal stratified TES calculated for different storage sizes and charge levels, based on (15) using Matlab

Figure 5: Storage losses, estimated by the previous TES model in DER-CAM, for different storage sizes and charge levels, based on (16) using Matlab

Figure 6: Storage losses, estimated by the improved DER-CAM TES model, for different storage sizes and charge levels, based on (9) using Matlab

Figure 7: Energy stored in the TES and the estimated storage losses for both TES models for building LHOT in San Diego for a weekday in March

Figure 8: Energy taken from storage for both TES models for building LCOLL in San Francisco for weekdays and weekends in January

\section{Table captions}

TABLE 1 LOAD DATA FOR THE BUILDINGS AND SITES IN THE CASE STUDY, [34]

TABLE 2 ELECTRICITY AND NATURAL GAS TARIFFS FOR ALL LOCATIONS AND BUILDINGS, [35]

TABLE 3 INVESTMENT COSTS FOR STORAGE, RENEWABLE, AND ELECTRIC TECHNOLOGIES, [35]1-[36]

TABLE 4 INVESTMENT COST FOR NATURAL GAS FIRED TECHNOLOGIES, [35]2

TABLE 5 PARAMETERS USED FOR BOTH TES MODELS

TABLE 6 CHANGE IN OPTIMAL TECHNOLOGY INVESTMENT COMPARED TO THE PREVIOUS VERSION OF DER-CAM, WITHOUT HP, CO2 MINIMIZATION

TABLE 7 CHANGE IN OPTIMAL TECHNOLOGY INVESTMENT COMPARED TO PREVIOUS VERSION OF DER-CAM, WITH HP, CO2 MINIMIZATION

TABLE 8 TECHNOLOGY INVESTMENT IN IMPROVED AND PREVIOUS MODEL, WITHOUT POSSIBILITY TO INVEST IN HP

TABLE 9 TECHNOLOGY INVESTMENT IN IMPROVED AND PREVIOUS MODEL, WITH POSSIBILITY TO INVEST IN HP

\section{Figure sizes}

All figures should be single column fitting except Figure 2 .

All tables should be 2 column fitting except Table 5

\footnotetext{
${ }^{1}$ Costs are assumed to be for the year 2020.

${ }^{2}$ Costs are assumed to be for the year 2020.
} 


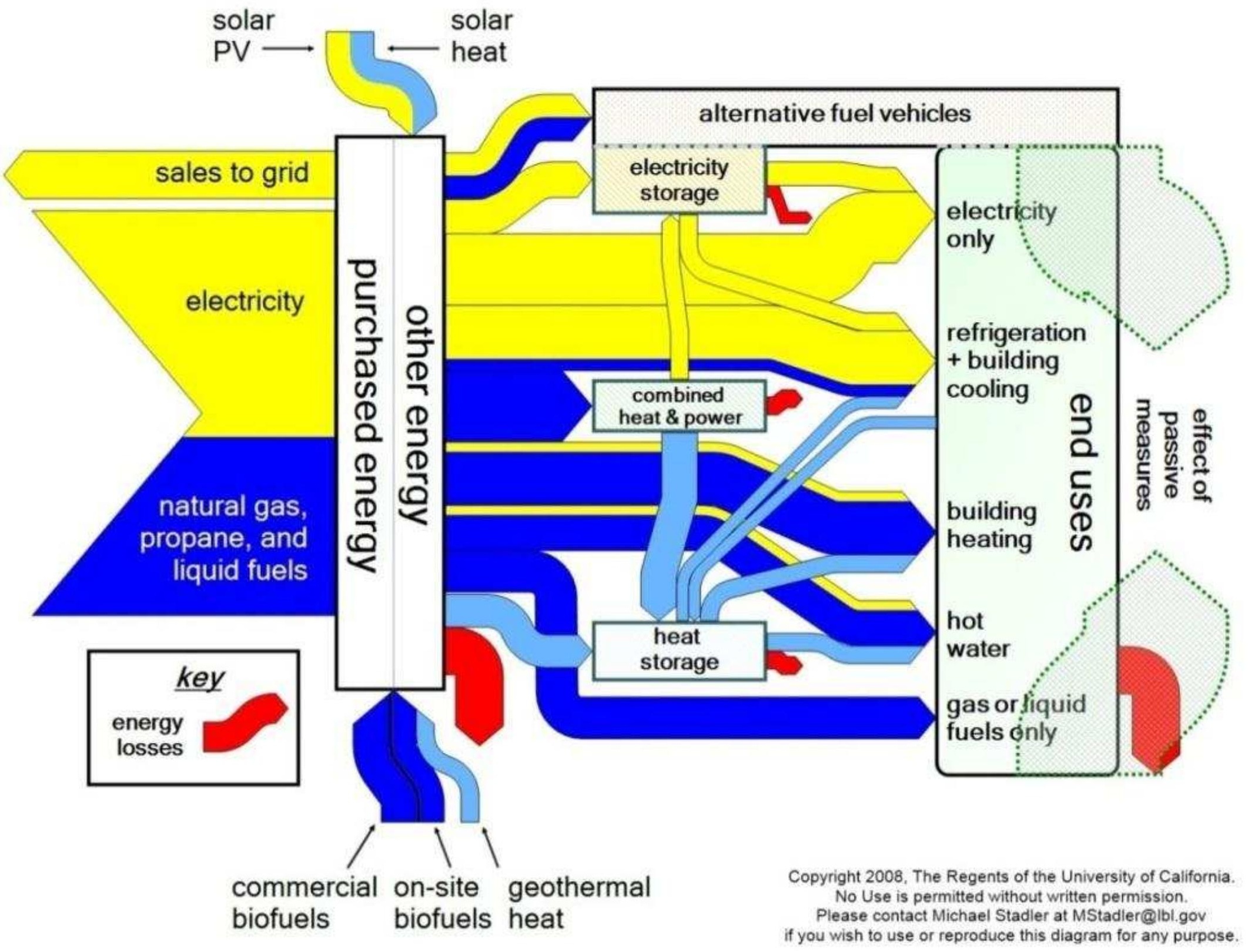


HT sources

- Natural gas

- Combined heat and power

- Solar thermal

- Heat recovered from NG chiller

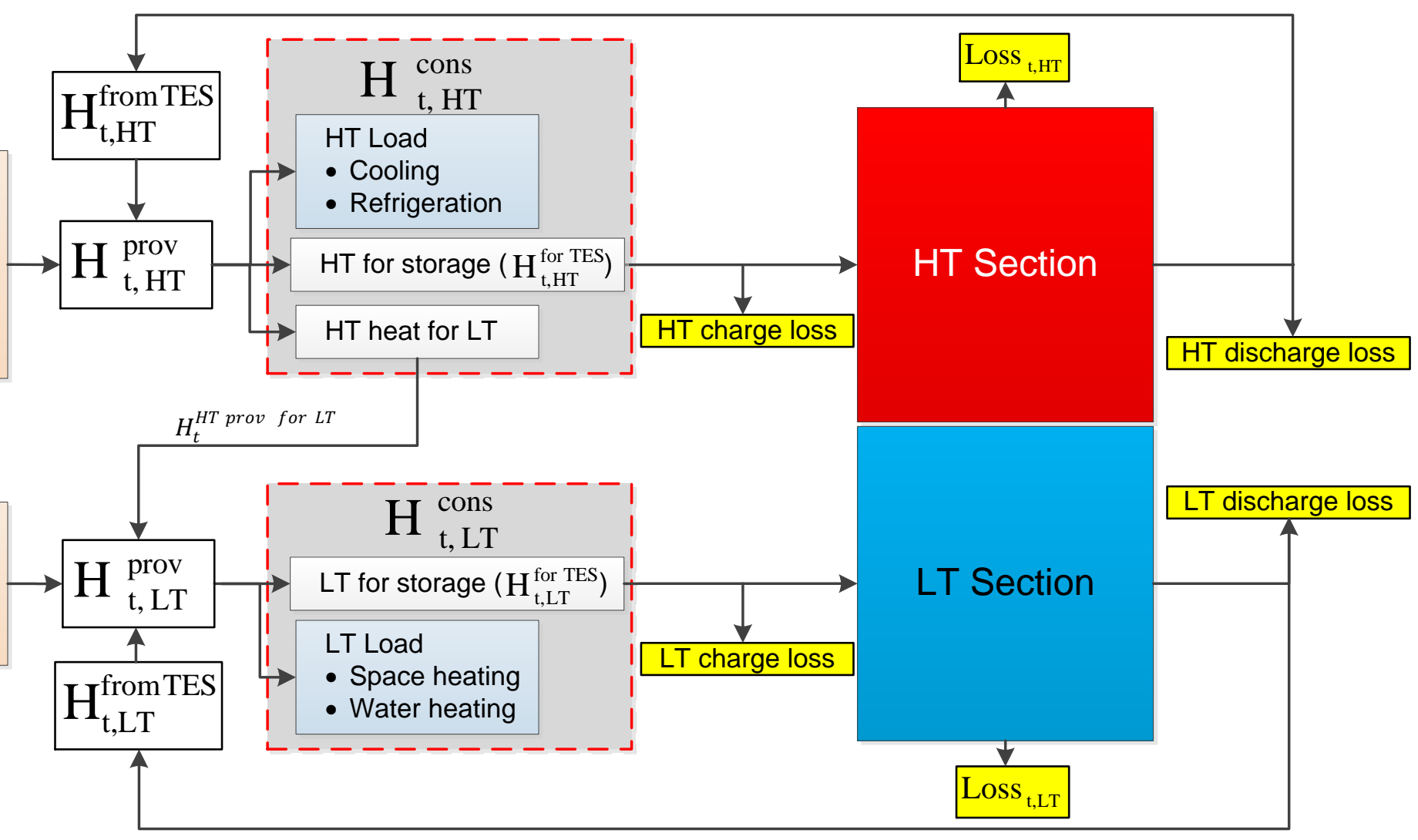

\section{LT sources}

- Alr source heat pump

- Ground source heat pump 


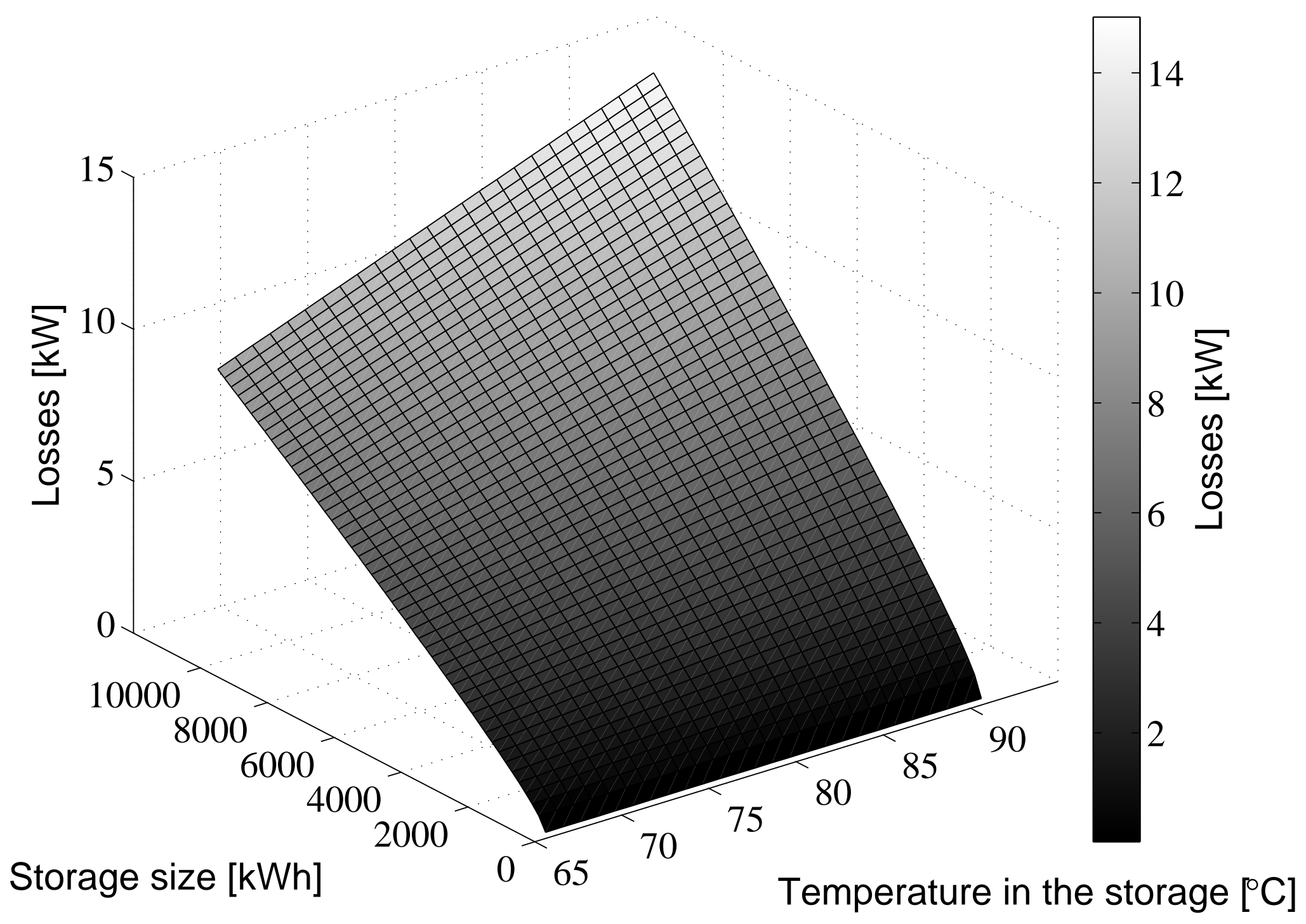




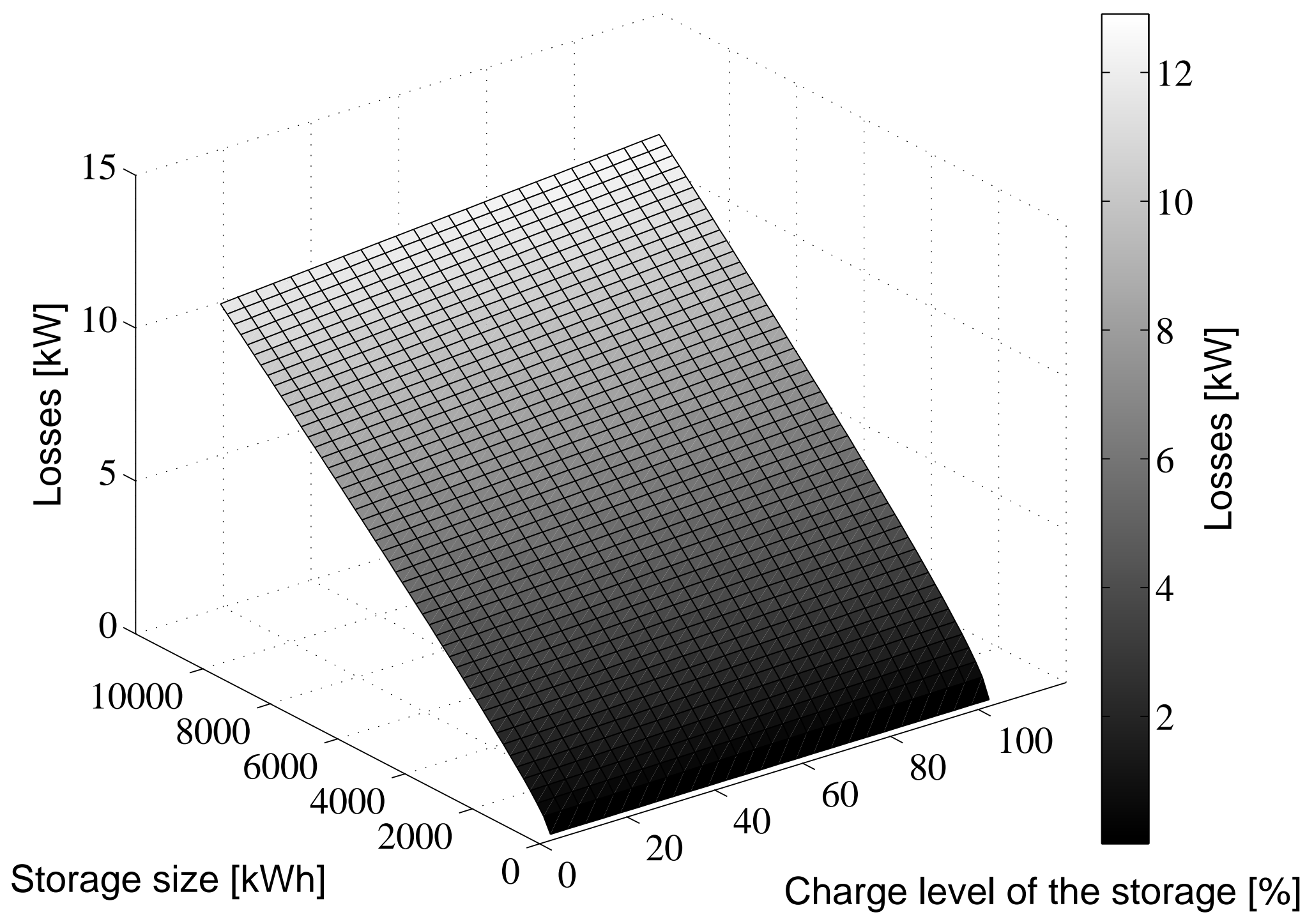




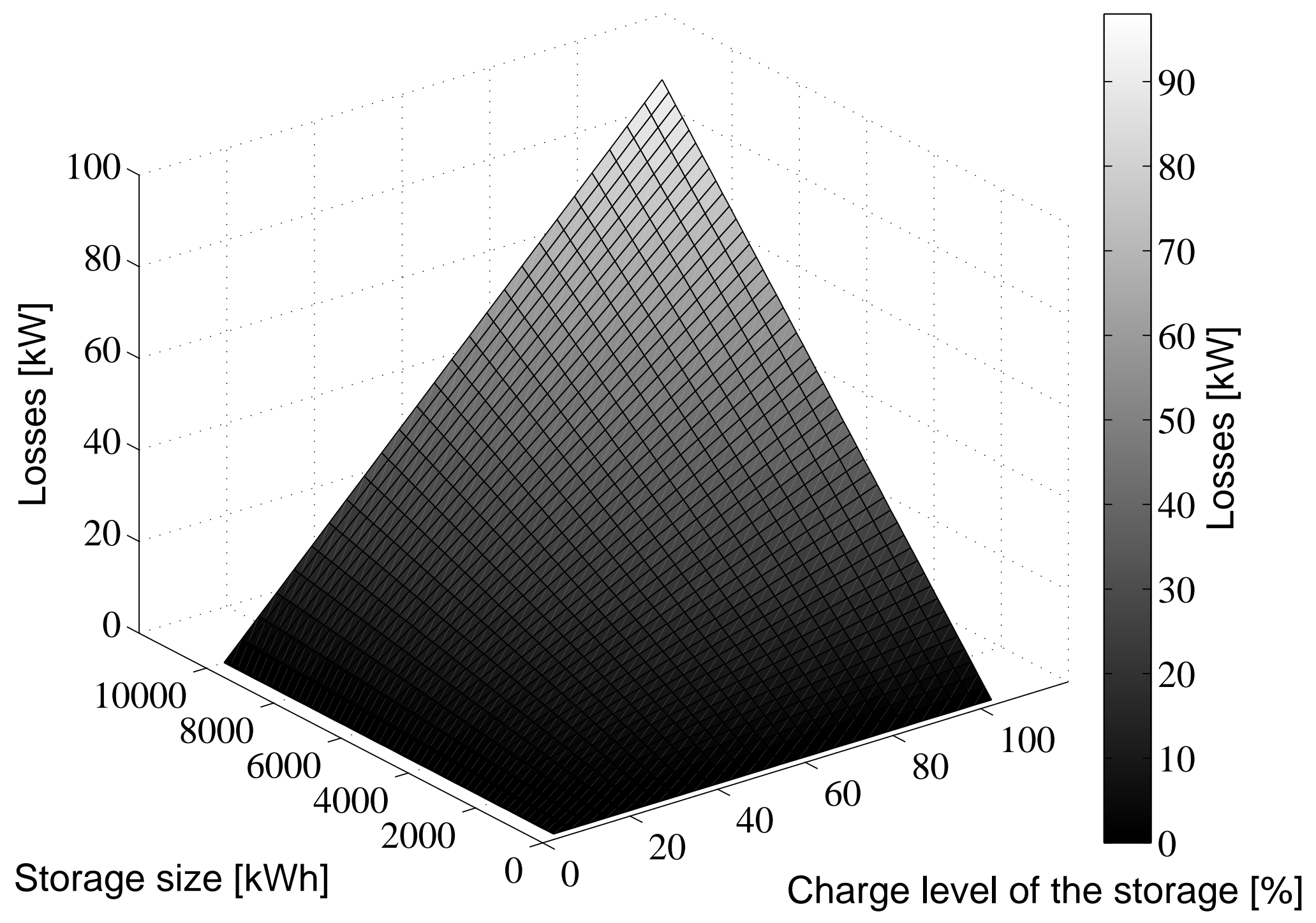




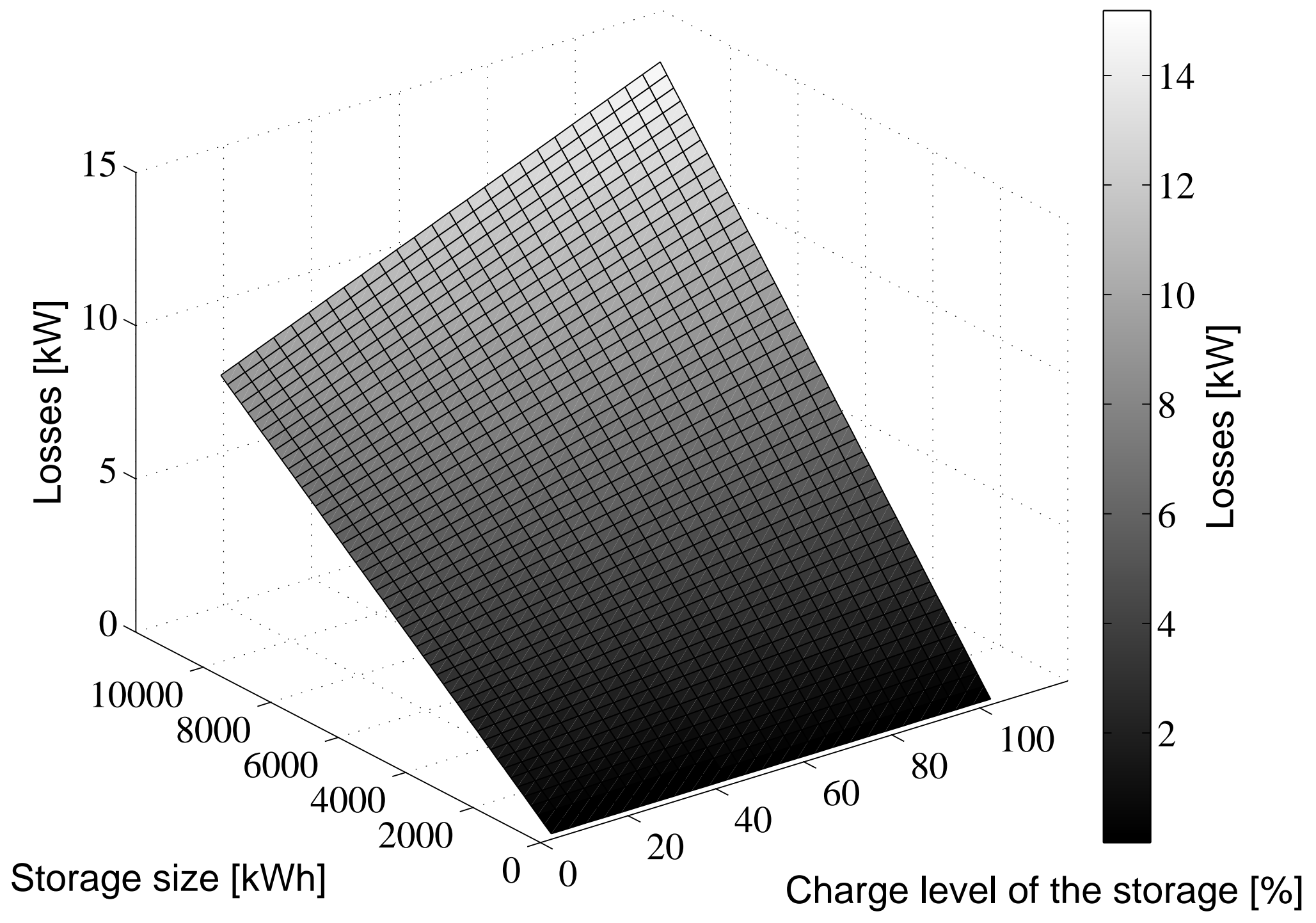



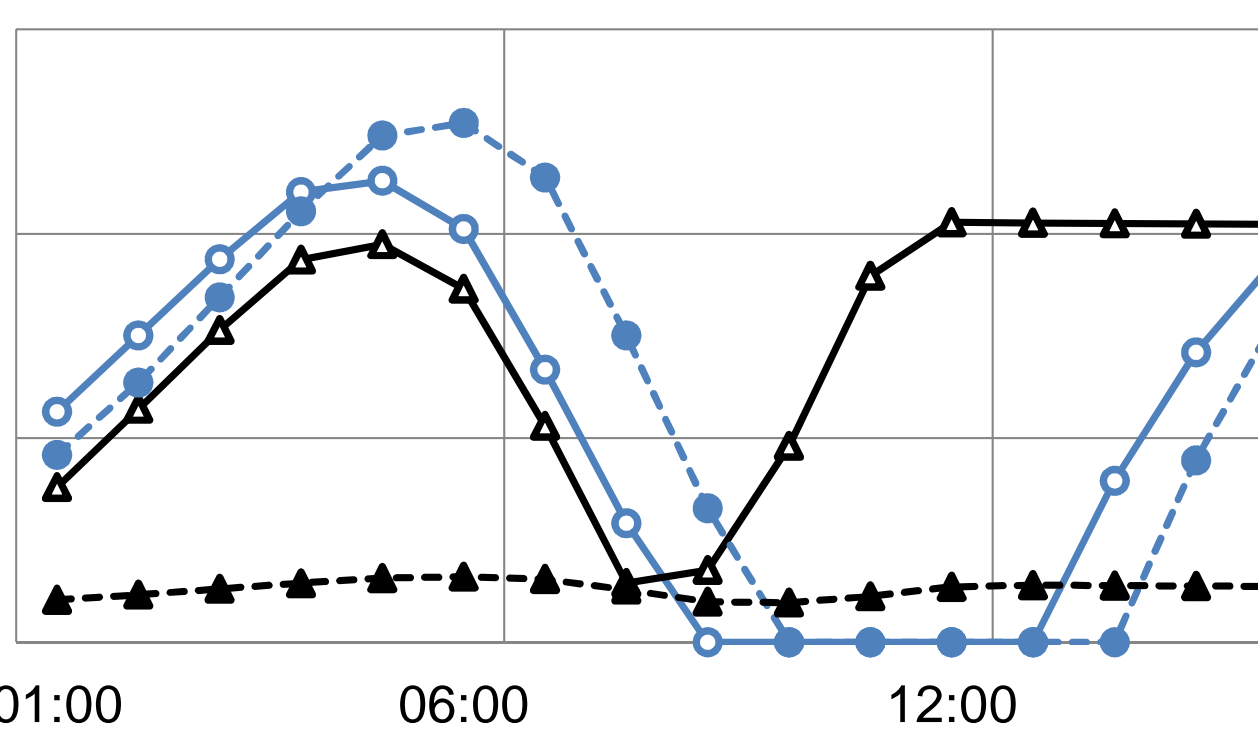

Time [Hour]

$-0-$ Heat stored in storage (previous model) $\rightarrow-$ Heat stored in storage (improved model)

- - Heat lost in storage (previous model)

$-₫$ - Heat lost in storage (improved model) 
Figure8

3000
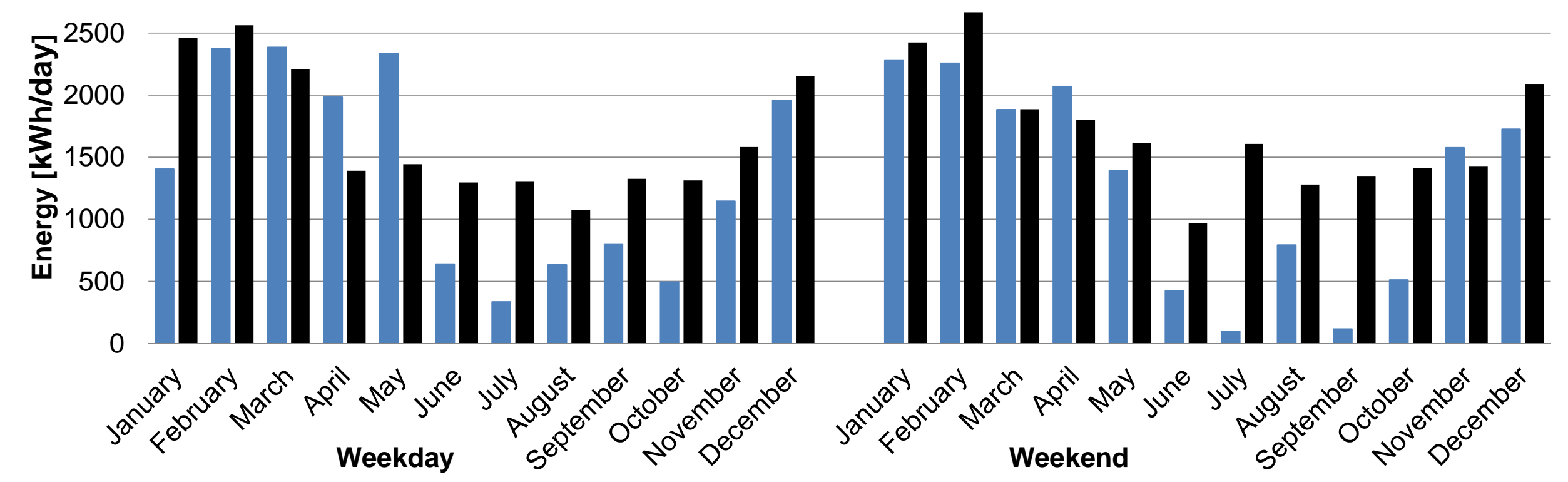

- Heat taken from TES (previous model)

- Heat taken from TES (improved model) 
TABLE 1: LOAD DATA FOR THE BUILDINGS AND SITES IN THE CASE STUDY, [34]

\begin{tabular}{|c|c|c|c|c|c|c|}
\hline Location: & \multicolumn{3}{|c|}{ San Francisco } & \multicolumn{3}{|c|}{ San Diego } \\
\hline Annual Demand for: & LCOLL & LHLTH & LHOT & LCOLL & LHLTH & LHOT \\
\hline Electricity-Only [MWh] & 14,788 & 8,917 & 4,377 & 18,028 & 9,579 & 4,782 \\
\hline Cooling [MWh $\left.\mathrm{M}_{\text {electricity demand }}\right]$ & 2,061 & 1,759 & 713 & 5,175 & 2,853 & 1,367 \\
\hline Space Heating [MWh] & 10,573 & 6,880 & 693 & 7,574 & 2,243 & 463 \\
\hline Water Heating [MWh] & 3,075 & 6,086 & 3,281 & 5,564 & 6,227 & 4,385 \\
\hline Natural Gas-Only [MWh] & 286 & 459 & 1,119 & 3,272 & 1,188 & 1,277 \\
\hline
\end{tabular}


TABLE 2: ELECTRICITY AND NATURAL GAS TARIFFS FOR ALL LOCATIONS AND BUILDINGS, [35]

\begin{tabular}{|c|c|c|c|c|c|c|c|}
\hline \multirow{3}{*}{\multicolumn{2}{|c|}{$\begin{array}{l}\text { Location: } \\
\text { Building type: } \\
\text { Season: }\end{array}$}} & \multicolumn{4}{|c|}{ San Francisco } & \multirow{2}{*}{\multicolumn{2}{|c|}{$\begin{array}{l}\text { San Diego } \\
\text { All buildings }\end{array}$}} \\
\hline & & \multicolumn{2}{|c|}{ LCOLL \& LHLTH } & \multicolumn{2}{|c|}{ LHOT } & & \\
\hline & & summer & winter & summer & winter & summer & winter \\
\hline \multicolumn{2}{|c|}{ Monthly electr. fee (\$) } & 2,029 & 2,029 & 769.47 & 769.47 & 338.77 & 338.77 \\
\hline \multirow{4}{*}{$\begin{array}{c}\text { Monthly } \\
\text { electricity } \\
\text { demand } \\
\text { rates }(\$ / \mathrm{kW})\end{array}$} & On-peak & 12.24 & - & 14.7 & - & 7 & 0.58 \\
\hline & Mid-peak & 2.65 & 0 & 3.43 & 0.21 & 0 & 0 \\
\hline & Off-peak & 0 & 0 & 0 & 0 & 0 & 0 \\
\hline & No coincident & 4.06 & 4.06 & 11.85 & 11.85 & 5.64 & 5.64 \\
\hline \multirow{3}{*}{$\begin{array}{l}\text { Electricity } \\
\text { rates } \\
(\$ c e n t / k W h)\end{array}$} & On-peak & 8.9 & - & 13.5 & - & 14 & 13.4 \\
\hline & Mid-peak & 7.57 & 7.7 & 9.6 & 9 & 12.2 & 12.7 \\
\hline & Off-peak & 6.4 & 6.7 & 7 & 7.3 & 10.3 & 10.8 \\
\hline \multirow{2}{*}{\multicolumn{2}{|c|}{$\begin{array}{l}\text { Monthly NG fee }(\$) \\
\text { NG rates }(\$ c e n t / k W h)\end{array}$}} & 48.35 & 48.35 & 48.35 & 48.35 & 10 & 10 \\
\hline & & 2.37 & 2.61 & 2.37 & 2.61 & 2.11 & 2.11 \\
\hline
\end{tabular}

Note: For San Diego: summer season May - September, on-peak hours 10-18 in summer and 16-20 in winter, mid-peak hours 5-10 and 18-21 in summer and 5-16 and 20-22 in winter, weekends and all other hours off-peak. For San Francisco: summer season May - October (April - October for NG), on-peak hours 12-18 in summer, mid-peak hours 8-12 and 18-22 in summer and 8-22 in winter, weekends and all other hours off-peak. 
TABLE 3: INVESTMENT COSTS FOR STORAGE, RENEWABLE, AND ELECTRIC TECHNOLOGIES, $[35]^{3}-[36]$

\begin{tabular}{lrrrr}
\hline \hline Parameter & $\begin{array}{r}\text { variable costs } \\
(\$ / \mathrm{kW} \text { or } \$ / \mathrm{kWh})\end{array}$ & $\begin{array}{r}\text { lifetime } \\
\text { (years })\end{array}$ & $\begin{array}{r}\text { fixed maintenance } \\
(\$ / \mathrm{kW} \text { or } \$ / \mathrm{kWh})\end{array}$ & $\begin{array}{r}\text { COP } \\
\text { heating/cooling }\end{array}$ \\
\hline Electric storage & $\$ 193 / \mathrm{kWh}_{\mathrm{e}}$ & 5 & 0.00 & --- \\
Thermal storage & $\$ 100 / \mathrm{kWh}_{\text {thermal }}$ & 17 & 0.00 & --- \\
Absorption chiller & $\$ 685 / \mathrm{kWh}_{\mathrm{e}}$ & 20 & 1.88 & -- \\
Photovoltaic & $\$ 3,237 / \mathrm{kW}_{\mathrm{e}}$ & 20 & 0.25 & -- \\
Solar thermal & $\$ 500 / \mathrm{kW}_{\text {thermal }}$ & 15 & 0.50 & --- \\
Air source HP & $\$ 1,121 / \mathrm{kW}_{\mathrm{e}}$ & 15 & 1.32 & $3.4 / 3.5$ \\
Ground source HP & $\$ 3,510 / \mathrm{kW}_{\mathrm{e}}$ & 20 & 6.3 & $4.9 / 8.1$ \\
\hline \hline
\end{tabular}

${ }^{3}$ Costs are assumed to be for the year 2020. 
TABLE 4: INVESTMENT COST FOR NATURAL GAS FIRED TECHNOLOGIES, [35] ${ }^{4}$

\begin{tabular}{lrrrrrr}
\hline \hline Technology & $\begin{array}{r}\text { Capacity } \\
{[\mathrm{kW}]}\end{array}$ & $\begin{array}{r}\text { Lifetime } \\
{[\text { Years }]}\end{array}$ & $\begin{array}{r}\text { Capital cost } \\
{[\$ / \mathrm{kW}]}\end{array}$ & $\begin{array}{r}\text { Maintenance } \\
\text { cost }[\$ / \mathrm{kWh}]\end{array}$ & $\begin{array}{r}\text { Efficiency } \\
{[\%]}\end{array}$ & HPR \\
\hline ICE-small & 60 & 20 & 2,098 & 0.021 & 29 & - \\
ICE-med & 250 & 20 & 1,143 & 0.015 & 30 & - \\
GT & 1,000 & 20 & 2,039 & 0.011 & 22 & - \\
MT-small & 60 & 10 & 2,116 & 0.017 & 28 & - \\
MT-med & 150 & 10 & 1,723 & 0.017 & 29 & - \\
FC-small & 100 & 10 & 4,969 & 0.033 & 46 & - \\
FC-med & 250 & 10 & 3,981 & 0.033 & 46 & - \\
ICE-HX-small & 60 & 20 & 2,760 & 0.021 & 29 & 1.73 \\
ICE-HX-med & 250 & 20 & 1,681 & 0.015 & 30 & 1.48 \\
GT-HX & 1,000 & 20 & 2,794 & 0.011 & 22 & 1.96 \\
MT-HX-small & 60 & 10 & 2,377 & 0.017 & 28 & 1.8 \\
MT-HX-med & 150 & 10 & 1,935 & 0.017 & 29 & 1.4 \\
FC-HX-small & 100 & 10 & 5,778 & 0.033 & 46 & 1 \\
FC-HX-med & 250 & 10 & 4,629 & 0.033 & 46 & 1 \\
FC-HX-small-wSGIP & 100 & 10 & 3,528 & 0.033 & 46 & 1 \\
FC-HX-med-wSGIP & 250 & 10 & 2,379 & 0.033 & 46 & 1 \\
\hline \hline
\end{tabular}

ICE: internal combustion engine, GT: gas turbine, MT: micro-turbine, FC: fuel cell, HX: heat exchanger for waste heat utilization, SGIP: California Self Generation Incentive which is basically an investment subsidy and provides $\$ 2.25 / W$ for natural gas fired fuel cells, today the subsidy has decreased to $\$ 2.03 / W$, in this study the higher subsidies has been used.

${ }^{4}$ Costs are assumed to be for the year 2020. 
TABLE 5: PARAMETERS USED FOR BOTH TES MODELS

Improved TES Previous

LT section HT section TES model

\begin{tabular}{|c|c|c|c|}
\hline$\eta_{\mathrm{ch}}(\%)$ & 90 & 90 & 90 \\
\hline$\eta_{\operatorname{disch}}(\%)$ & 90 & 90 & 90 \\
\hline $\max { }^{\text {ch. rate }}(\%)$ & 25 & 25 & 25 \\
\hline $\max { }^{\text {disch. rate }}(\%)$ & 25 & 25 & 25 \\
\hline$\theta^{\text {storage }}(\%)$ & 0.057 & 0.060 & 1 \\
\hline$\theta^{\text {static }}(\%)$ & 0.056 & 0.053 & --- \\
\hline $\mathrm{T}^{\min }\left({ }^{\circ} \mathrm{C}\right)$ & 36 & 65 & --- \\
\hline $\mathrm{T}^{\max }\left({ }^{\circ} \mathrm{C}\right)$ & 65 & 90 & --- \\
\hline
\end{tabular}


TABLE 6: CHANGE IN OPTIMAL TECHNOLOGY INVESTMENT COMPARED TO THE PREVIOUS VERSION OF DER-CAM, WITHOUT HP, CO2 MINIMIZATION

\begin{tabular}{lccc|ccc}
\hline \hline Change in technology & \multicolumn{3}{c|}{ San Francisco } & \multicolumn{4}{c}{ San Diego } \\
investment excl. HP [\%] & LCOLL & LHLTH & LHOT & LCOLL & LHLTH & LHOT \\
\hline DG without HX & - & - & - & $\mathbf{- 1 0 0}$ & inf & - \\
CHP (DG with HX) & -7 & $\mathbf{0}$ & $\mathbf{0}$ & $\mathbf{2 4}$ & $\mathbf{- 1 5}$ & $\mathbf{0}$ \\
Electric Storage & -65 & -14 & -3 & -24 & -18 & -3 \\
TES (LT section) & -100 & -100 & -14 & 158 & -5 & -28 \\
TES (HT section) & -100 & -100 & -100 & -100 & -100 & -100 \\
TES (LT + HT section) & $\mathbf{- 1 0 0}$ & $\mathbf{- 1 0 0}$ & $\mathbf{- 1 4}$ & $\mathbf{1 5 8}$ & $\mathbf{- 5}$ & $\mathbf{- 2 8}$ \\
Abs. Chiller & 15 & -100 & 56 & 21 & -20 & -5 \\
PV & -7 & inf & -2 & 0 & 0 & -2 \\
Solar Thermal & -100 & -75 & 21 & - & - & 14 \\
Annual CO Emissions & $\mathbf{7}$ & $\mathbf{4}$ & $\mathbf{- 1}$ & $\mathbf{- 1}$ & $\mathbf{3}$ & $\mathbf{0}$ \\
Annual Energy Costs & -6 & 0 & -1 & 6 & -8 & 3 \\
\hline \hline
\end{tabular}

Note: ‘-' means no investment in any model, 'inf' means no investment in old model, '-100' means no investment in new model. 
TABLE 7: CHANGE IN OPTIMAL TECHNOLOGY INVESTMENT COMPARED TO PREVIOUS VERSION OF DER-CAM, WITH HP, CO2 MINIMIZATION

\begin{tabular}{|c|c|c|c|c|c|c|}
\hline \multirow{2}{*}{$\begin{array}{l}\text { Change in technology } \\
\text { investment incl. HP [\%] }\end{array}$} & \multicolumn{3}{|c|}{ San Francisco } & \multicolumn{3}{|c|}{ San Diego } \\
\hline & LCOLL & LHLTH & LHOT & LCOLL & LHLTH & LHOT \\
\hline DG without HX & - & - & - & -100 & -95 & - \\
\hline CHP (DG with HX) & -8 & $\mathbf{0}$ & -18 & 16 & 58 & -13 \\
\hline Electric Storage & -58 & -5 & 9 & -12 & 6 & 59 \\
\hline TES (LT section) & -100 & -100 & -22 & 14 & 62 & 18 \\
\hline TES (HT section) & -100 & -100 & -100 & -100 & -100 & -100 \\
\hline TES (LT + HT section) & -100 & -100 & -22 & 14 & 62 & 18 \\
\hline Air Source HP & - & 14 & -100 & Inf & 113 & 175 \\
\hline Ground Source HP & -30 & -21 & 9 & 1 & 7 & 27 \\
\hline Abs. Chiller & -6 & -100 & 58 & -9 & 73 & 165 \\
\hline PV & -19 & 10 & -5 & 0 & 0 & -5 \\
\hline Solar Thermal & - & -79 & Inf & - & - & 269 \\
\hline Annual $\mathrm{CO}_{2}$ Emissions & 9 & $\mathbf{0}$ & 3 & $\mathbf{0}$ & -3 & -2 \\
\hline Annual Energy Costs & -2 & 2 & 0 & 5 & 12 & 1 \\
\hline
\end{tabular}

Note: ‘-' means no investment in any model, 'inf’ means no investment in old model, ‘-100' means no investment in new model. 
TABLE 8: TECHNOLOGY INVESTMENT IN IMPROVED AND PREVIOUS MODEL, WITHOUT POSSIBILITY TO INVEST IN HP

\begin{tabular}{|c|c|c|c|c|c|c|}
\hline \multirow{2}{*}{$\begin{array}{c}\text { Technology investment } \\
\text { excl. HP }[\mathrm{kW}]\end{array}$} & \multicolumn{3}{|c|}{ San Francisco } & \multicolumn{3}{|c|}{ San Diego } \\
\hline & LCOLL & LHLTH & LHOT & LCOLL & LHLTH & LHOT \\
\hline ICE-small & $0(0)$ & $0(0)$ & $0(0)$ & $0(2,760)$ & $1,560(0)$ & $0(0)$ \\
\hline DG without $\mathbf{H X}$ & $\mathbf{0}(\mathbf{0})$ & $\mathbf{0}(\mathbf{0})$ & $\mathbf{0}(\mathbf{0})$ & $0(2,760)$ & $1,560(0)$ & $\mathbf{0}(\mathbf{0})$ \\
\hline ICE-HX-small & $0(0)$ & $0(0)$ & $0(0)$ & $0(0)$ & $0(0)$ & $0(60)$ \\
\hline ICE-HX-med & $500(0)$ & $0(0)$ & $0(0)$ & $0(0)$ & $0(0)$ & $0(0)$ \\
\hline MT-HX-small & $0(0)$ & $0(0)$ & $0(0)$ & $0(0)$ & $0(0)$ & $60(0)$ \\
\hline FC-HX-small & $0(0)$ & $0(0)$ & $0(0)$ & $500(300)$ & $100(300)$ & $0(0)$ \\
\hline FC-HX-med & $0(0)$ & $0(0)$ & $0(0)$ & $750(250)$ & $250(1,250)$ & $250(250)$ \\
\hline FC-HX-small-wSGIP & $100(0)$ & $100(100)$ & $300(300)$ & $700(600)$ & $300(100)$ & $400(400)$ \\
\hline FC-HX-med-wSGIP & $1,500(2,250)$ & $1,250(1,250)$ & $250(250)$ & $2,250(2,250)$ & $750(0)$ & $250(250)$ \\
\hline DG with HX & $2,100(2,250)$ & $1,350(1,350)$ & $550(550)$ & $4,200(3,400)$ & $1,400(1,650)$ & $960(960)$ \\
\hline Electric Storage & $2,553(7,192)$ & $3,222(3,745)$ & $2,518(2,598)$ & $10,374(13,673)$ & $2,465(3,016)$ & $2,227(2,285)$ \\
\hline TES (LT strata) & $0(-)$ & $0(-)$ & $1,501(-)$ & $12,028(-)$ & $2,115(-)$ & $1,501(-)$ \\
\hline TES (HT strata) & $0(-)$ & $0(-)$ & $0(-)$ & $0(-)$ & $0(-)$ & $0(-)$ \\
\hline TES (LT + HT strata) & $0(2,479)$ & $0(8,997)$ & $1,501(1,737)$ & $12,028(4,666)$ & $2,115(2,236)$ & $1,501(2,081)$ \\
\hline Abs. Chiller & $174(152)$ & $0(275)$ & $86(55)$ & $412(342)$ & $118(147)$ & $109(115)$ \\
\hline PV & $686(741)$ & $319(0)$ & $492(502)$ & $856(856)$ & $498(498)$ & $474(484)$ \\
\hline Solar Thermal & $0(229)$ & $604(2,445)$ & $286(236)$ & $0(0)$ & $0(0)$ & $373(327)$ \\
\hline Annual $\mathrm{CO}_{2}$ Emissions & $7,174(6,708)$ & $4,845(4,665)$ & $1,956(1,975)$ & $9,172(9,237)$ & $4,850(4,727)$ & $2,396(2,406)$ \\
\hline Annual Energy Costs & $2,213(2,348)$ & $1,608(1,605)$ & $814(824)$ & $4,270(4,030)$ & $1,951(2,110)$ & $1,076(1,049)$ \\
\hline
\end{tabular}

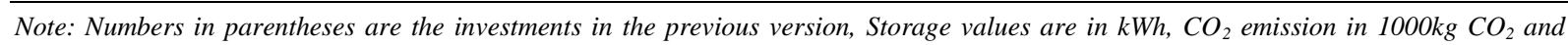
energy cost in $1000 \$$ 
TABLE 9: TECHNOLOGY INVESTMENT IN IMPROVED AND PREVIOUS MODEL, WITH POSSIBILITY TO INVEST IN HP

\begin{tabular}{|c|c|c|c|c|c|c|}
\hline \multirow{2}{*}{$\begin{array}{c}\text { Technology investment } \\
\text { incl. HP }[\mathrm{kW}]\end{array}$} & \multicolumn{3}{|c|}{ San Francisco } & \multicolumn{3}{|c|}{ San Diego } \\
\hline & LCOLL & LHLTH & LHOT & LCOLL & LHLTH & LHOT \\
\hline ICE-small & $0(0)$ & $0(0)$ & $0(0)$ & $0(1680)$ & $0(1860)$ & $0(0)$ \\
\hline FC-small & $0(0)$ & $0(0)$ & $0(0)$ & $0(0)$ & $100(0)$ & $0(0)$ \\
\hline DG without $\mathrm{HX}$ & $\mathbf{0}(\mathbf{0})$ & $\mathbf{0}(\mathbf{0})$ & $\mathbf{0}(\mathbf{0})$ & $0(3,360)$ & $100(0)$ & $\mathbf{0}(\mathbf{0})$ \\
\hline FC-HX-small & $0(0)$ & $0(0)$ & $0(0)$ & $600(200)$ & $100(0)$ & $300(100)$ \\
\hline FC-HX-med & $0(0)$ & $0(0)$ & $0(0)$ & $0(500)$ & $500(250)$ & $0(250)$ \\
\hline FC-HX-small-wSGIP & $100(0)$ & $200(200)$ & $200(300)$ & $600(500)$ & $200(300)$ & $100(400)$ \\
\hline FC-HX-med-wSGIP & $1,500(2,000)$ & $1,000(1,000)$ & $250(250)$ & $2,500(2,000)$ & $1,250(750)$ & $250(0)$ \\
\hline CHP (DG with HX) & $1,850(2,000)$ & $1,200(1,200)$ & $450(550)$ & $3,700(3,200)$ & $2,050(1,300)$ & $650(750)$ \\
\hline Electric Storage & $2,361(5,612)$ & $1,839(1,935)$ & $2,853(2,607)$ & $9,017(10,240)$ & $1,906(1,793)$ & $2,737(1,722)$ \\
\hline TES (LT strata) & $0(0)$ & $0(0)$ & $0(0)$ & $0(0)$ & $0(0)$ & $0(0)$ \\
\hline TES (HT strata) & $0(0)$ & $0(0)$ & $1,346(0)$ & $13,306(0)$ & $3,143(0)$ & $1,806(0)$ \\
\hline TES (LT + HT strata) & $0(5,138)$ & $0(5,365)$ & $1,346(1,735)$ & $13,306(11,624)$ & $3,143(1,943)$ & $1,806(1,528)$ \\
\hline Air Source HP & $0(0)$ & $190(166)$ & $0(55)$ & $128(0)$ & $119(56)$ & $256(93)$ \\
\hline Ground Source HP & $191(274)$ & $267(339)$ & $135(124)$ & $848(836)$ & $420(391)$ & $214(169)$ \\
\hline Abs. Chiller & $146(155)$ & $0(16)$ & $63(40)$ & $482(528)$ & $192(111)$ & $61(23)$ \\
\hline PV & $695(856)$ & $487(444)$ & $520(550)$ & $856(856)$ & $498(498)$ & $510(539)$ \\
\hline Solar Thermal & $0(0)$ & $55(268)$ & $149(0)$ & $0(0)$ & $0(0)$ & $199(54)$ \\
\hline Annual $\mathrm{CO}_{2}$ Emissions & $6,898(6,348)$ & $4,231(4,214)$ & $1,908(1,847)$ & $8,529(8,567)$ & $4,322(4,459)$ & $2,231(2,284)$ \\
\hline Annual Energy Costs & $2,201(2,242)$ & $1,509(1,476)$ & $806(803)$ & $4,094(3,906)$ & $2,062(1,843)$ & $1,033(1,026)$ \\
\hline
\end{tabular}

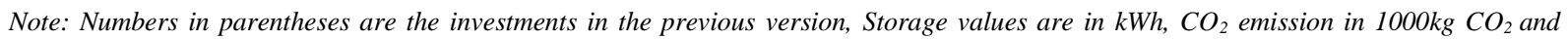
energy cost in $1000 \$$ 